\title{
Interaction of Dietary Fatty Acids with Tumour Necrosis Factor Family Cytokines during Colon Inflammation and Cancer
}

\author{
Jiřina Hofmanová, ${ }^{1}$ Nicol Straková, ${ }^{1}$ Alena Hyršlová Vaculová, ${ }^{1}$ Zuzana Tylichová, ${ }^{1,2}$ \\ Barbora Šafaříková, ${ }^{1,2}$ Belma Skender, ${ }^{1}$ and Alois Kozubík ${ }^{1,2}$ \\ ${ }^{1}$ Department of Cytokinetics, Institute of Biophysics, Academy of Sciences of the Czech Republic, v.v.i., Královopolská 135, \\ 61265 Brno, Czech Republic \\ ${ }^{2}$ Institute of Experimental Biology, Department of Animal Physiology and Immunology, Faculty of Science, Masaryk University, \\ Kotlářská 2, 61137 Brno, Czech Republic
}

Correspondence should be addressed to Jiřina Hofmanová; hofmanova@ibp.cz

Received 14 February 2014; Accepted 29 March 2014; Published 30 April 2014

Academic Editor: Arkadiusz Orzechowski

Copyright ( 2014 Jiřina Hofmanová et al. This is an open access article distributed under the Creative Commons Attribution License, which permits unrestricted use, distribution, and reproduction in any medium, provided the original work is properly cited.

\begin{abstract}
Intestinal homeostasis is precisely regulated by a number of endogenous regulatory molecules but significantly influenced by dietary compounds. Malfunction of this system may result in chronic inflammation and cancer. Dietary essential n-3 polyunsaturated fatty acids (PUFAs) and short-chain fatty acid butyrate produced from fibre display anti-inflammatory and anticancer activities. Both compounds were shown to modulate the production and activities of TNF family cytokines. Cytokines from the TNF family (TNF- $\alpha$, TRAIL, and FasL) have potent inflammatory activities and can also regulate apoptosis, which plays an important role in cancer development. The results of our own research showed enhancement of apoptosis in colon cancer cells by a combination of either docosahexaenoic acid (DHA) or butyrate with TNF family cytokines, especially by promotion of the mitochondrial apoptotic pathway and modulation of NFKB activity. This review is focused mainly on the interaction of dietary PUFAs and butyrate with these cytokines during colon inflammation and cancer development. We summarised recent knowledge about the cellular and molecular mechanisms involved in such effects and outcomes for intestinal cell behaviour and pathologies. Finally, the possible application for the prevention and therapy of colon inflammation and cancer is also outlined.
\end{abstract}

\section{Introduction}

Immune homeostasis in the intestine is tightly regulated by crosstalk between commensal bacteria, mucosal immune cells, and intestinal epithelial cells. These cells migrate from their place of origin at the crypt base to the villus (small intestine) or crypt (large bowel) tip, from where they are shed into the lumen. Dynamic balance between cell production at the base and cell death at the surface of the colonic crypts is precisely regulated by a number of physiological endogenous factors. In addition to hormones and cytokines, specific signalling through Wnt, Notch, and BMP pathways are essential for intestinal development and homeostasis [1]. Irregularities of such regulation might cause different pathologies including colon cancer. Recently, various types of cell death and their crosstalk were identified in the intestinal epithelium. In addition to apoptosis, autophagy and necroptosis were described as other modes of programmed colon cell death. Excessive cell death has been associated with chronic inflammation in patients with Crohn's disease and ulcerative colitis (UC) and dysregulation of cell death also plays essential role in colorectal cancer (CRC) [2].

The pathogenesis of CRC is a long and multifactorial process which involves not only mutations in specific oncogenes and tumour suppressor genes, but also alterations in gene expression which are induced by epigenetic and nongenotoxic mechanisms $[3,4]$. Disturbed regulation of apoptosis and loss of sensitivity to apoptosis-inducing factors are some of the key mechanisms in CRC development [5, 6]. Further, autophagy, process of cellular self-digestion, has been demonstrated to promote cancer cell survival and drug resistance, but on the other hand it may function as a tumour 
suppressor mechanism [7]. Moreover, an association between inflammation and cancer has been suggested for a long time [8]. Patients with inflammatory bowel disease (IBD) have a significantly increased risk of developing malignancy in the colon $[9,10]$. An important role is especially played by increased production of various endogenous inflammatory molecules and malfunction of the immune system. However, some types of these molecules, such as tumour necrosis factor (TNF) family cytokines, may play a dual role. Their overproduction supports inflammation, but they can also induce death receptor-mediated apoptosis in certain cell types [11].

Nowadays it is clear that, in addition to endogenous regulators influencing cell and tissue homeostasis, lifestyle factors (mainly smoking, composition of the diet, and physical activity) play a role in the aetiology of colon inflammation and cancer $[12,13]$. Among them, various types of fatty acids originating from dietary fat and fibre are being investigated to clarify the role and possible mechanisms by which they may influence colonic health [14-17].

The results of some studies including our own also suppose that there is mutual interaction between physiological regulators of cell behaviour and dietary lipids, which may positively or negatively influence the maintenance of intestinal tissue homeostasis. In the intestine, signals from nutritional compounds and endogenous factors, which play a role in inflammatory response and regulate cell growth, differentiation, and apoptosis, are integrated within the cell and may have a substantial impact determining the final phenotype, metabolism, and kinetics of epithelial cell population. Moreover, an altered sensitivity and response of transformed cells to these signals play the role during colon carcinogenesis.

In this review we focused on the role and mechanisms of action of dietary essential polyunsaturated fatty acids (PUFAs), short-chain fatty acid (SCFA) butyrate from fibre, and their interaction with TNF family cytokines during colon inflammation and cancer.

\section{Chronic Inflammation Drives Cancer Development}

Chronic inflammation is considered as one of the key mechanisms promoting and accelerating cancer development. This process mainly involves continuous activity of various cytokines, chemokines, production of reactive oxygen and nitrogen species (RONS), activity of certain enzymes, and activation of specific signalling pathways and transcription factors [18].

The inflammation present in the tumour microenvironment is characterised by leukocyte infiltration. These cells produce a variety of cytotoxic mediators such as RONS, proteases, matrix metalloproteinases, TNF- $\alpha$, interleukins (IL), interferons (IFN), and enzymes such as cyclooxygenase2 (COX-2), 5-lipoxygenase (5-LOX), and phospholipase A2 (PLA2) responsible for eicosanoid formation. Such mediators activate specific transcription factors: nuclear factor $\kappa \mathrm{B}(\mathrm{NF}-\kappa \mathrm{B}), \mathrm{AP}-1$ or hypoxia-inducing factor $1 \alpha$ (HIF-1), and signal transducers like Janus kinase/Signal transducers and activators of transcription 3 (JAK/STAT3) [19]. These conditions can induce genetic and epigenetic changes including various types of mutations, chromosomal aberrations, methylation of various tumour-related genes, and modulated expression of microRNAs. These events work in concert to alter the important pathways involved in the normal cellular function and hence accelerate inflammation-associated cancer development [20].

2.1. Intestinal Inflammation and Cancer. In patients with IBD, chronic inflammation represents a major risk factor for the development of CRC [21]. This process leads to a disruption of the epithelial barrier and the formation of epithelial ulceration [22]. It permits easy access for the luminal microbiota and dietary antigens to cells resident in the lamina propria and stimulates further pathological immune cell responses [23]. However, the mechanisms underlying this neoplastic transformation are not fully understood. Studies in experimental models of CRC suggest that inflammatory cellderived cytokines either directly or indirectly stimulate the uncontrolled growth of cancer cells [24].

Despite the differences between the molecular abnormalities found in colitis-associated dysplasia in comparison with sporadic CRC, there are many similarities (dysplasia-cancer sequence, similar frequencies of major chromosomal abnormalities, microsatellite instability, and similar glycosylation changes) that make it reasonable to suggest that also sporadic colon cancer might be largely secondary to inflammation. The fact that regular use of nonsteroidal anti-inflammatory drugs (NSAIDs) can lower the mortality and result in regression of adenomas in familial adenomatous polyposis (FAP) patients with mutation in the adenomatous polyposis coli (APC) gene brings further evidence of the role of inflammation in CRC [25]. However, this process may function as a double-edged sword. Under specific inflammatory conditions, immune cells can boost an antitumour immune response with the downstream effect of eliminating dysplastic and cancerous cells. Thus, inflammation can play both a beneficial and a detrimental role in colon carcinogenesis [26, 27]. Since understanding of the definition and pathogenesis of CRC in IBD is crucial to optimise patient management, further investigation is necessary.

\section{The Role of Cytokines in Colon Inflammation and Cancer}

A variety of immune mediated bowel disorders, including celiac disease, Crohn's disease, and UC, are characterized by accelerated epithelial cell turnover and cell death leading to altered crypt morphology. These changes are mediated by the cytokines released from infiltrating inflammatory cells and enterocytes in paracrine or autocrine fashion, respectively. Similarly, various types of cytokines and chemokines, which can be produced by tumour cells themselves or by the cells in the tumour microenvironment, play an important role in colon cancer development. Using a mouse model of UC, TNF- $\alpha$ has been identified as a crucial mediator of the initiation and progression of colitis-associated CRC [28]. 
Proinflammatory molecules promote the growth of tumour cells, perturb their differentiation, and support the survival of cancer cells [23]. TNF- $\alpha$, interleukins (IL- 6 and IL-1 $\beta$ ), or transcription factors (NF- $\kappa \mathrm{B}$ and STATs) that are required for signalling by these cytokines are indeed emerging as potential targets for anticancer therapy. Members of the IL12 family have been implicated in the pathogenesis of colitis, and IL-23 seems to be involved in inflammation-associated carcinogenesis [29]. The described mediators and activated signalling pathways generally delay or suppress the apoptosis of intestinal cells and modulate angiogenesis and drugmetabolising enzyme induction [30]. It was also reported that the colonic mucosa of UC patients displayed an increased T-cell infiltration. Moreover, the disbalance between CD4+ T-helper subsets (Th1 and Th2) producing specific inflammatory cytokines in the intestine and their resistance to apoptosis contributes to chronic mucosal inflammation [31]. Experiments using the Apc (Min/+) mouse model confirmed the association between intestinal cytokines and tumorigenesis. The overall polyp number and abundance of large polyps significantly correlated with inflammatory cytokine (IL-1, IL-6, and TNF- $\alpha$ ) response. Inflammatory mediators may thus serve as important biomarkers for CRC progression [32]. Next, we focused on the role of TNF family cytokines.

3.1. Dual Role of TNF Family Cytokines. The TNF superfamily is composed of 19 ligands and 29 receptors, which play a highly diverse role in the body. This implies that at least some of the ligands have to interact with more than one receptor. All ligands and their receptors are well described in a recent work of Aggarwal et al. [33]. Without exception, the TNF superfamily exhibits a proinflammatory activity; in part through activation of the transcription factor NF- $\kappa \mathrm{B}$. However, these cytokines are involved in the regulation of not only inflammation but also cellular proliferation, apoptosis, and morphogenesis [11, 34]. Cell signalling is mediated through the interaction between transmembrane receptors and either soluble or transmembrane ligands. TNF- $\alpha$, TRAIL (tumour necrosis factor-related apoptosis-inducing ligand), or Fas ligand (FasL), are expressed in both forms. Members of the TNF superfamily can be classified into those groups with or without an intracellular death domain (DD), and they have been identified as important participants in the regulation of apoptosis [35]. The death domain, a region of approximately 45 amino acids long, plays a crucial role in transmitting the death signals from the cell surface to the intracellular pathways $[33,36]$. The cytokines TNF- $\alpha$, FasL, and TRAIL induce apoptosis by binding to their receptors TNFR1/2, Fas, and DR4/DR5, respectively, which possess intracellular DDs recruiting certain adaptor molecules to form the death-inducing signalling complex (DISC) consisting of Fas-associated DD protein (FADD) and procaspase- 8 [37]. The activation of caspase- 8 at the DISC can be potently regulated by cellular FLICE-like inhibitory protein (cFLIP). In the so-called type I cells, efficient caspase- 8 activation is followed by a direct cleavage of effector caspases (extrinsic apoptotic pathway), while type II cells mostly use caspase- 8 to cleave the Bid protein, which is responsible for translocation of the apoptotic signal to mitochondria (intrinsic apoptotic pathway) [38]. Changes in mitochondria (mitochondrial transition pore opening, decrease of mitochondrial membrane potential, and production of ROS) are associated with the activation of pro- and antiapoptotic proteins of the $\mathrm{Bcl}-2$ family, which play a crucial role in the release of proapoptotic proteins (cytochrome c, Smac/DIABLO) into the cytosol. The subsequent activation of caspase-9 is followed by activation of effector caspases, cleavage of poly ADP-ribose polymerase (PARP), and overall apoptosis. Caspase activity can be effectively modulated by the inhibitor of apoptosis proteins (IAPs) [39].

Recently, another mode of caspase-independent, nonapoptotic programmed cell death induced by stimulating death receptors named necroptosis was detected. This process shares some signalling pathways and molecules with apoptosis and its interaction with autophagy is also suggested. Necroptosis contributes to regulation of immune system and plays a role in cancer development [40]. It is associated with increased expression of receptor-interacting proteins RIP1/RIP3 and erroneous function of FADD and caspase- 8 which may be critical for regulation of intestinal homeostasis [2]. Association of necroptosis and intestinal inflammation through specific activation of TNF- $\alpha$ synthesis by RIP1 and Akt kinase pathway has been documented [41].

In summary, TNF cytokines may play a dual role in the intestine; they have potent proinflammatory activities, but they also function as regulators of apoptosis associated with cancer development. It seems that cell proliferation, survival, and apoptosis are activated simultaneously by TNF members and the balance in their production and activation significantly determines the fate of the cells and contributes to intestinal homeostasis. Excessive programmed cell death promotes inflammation and, on the other hand, resistance to apoptosis contributes to cancer development. However, molecular mechanisms are not fully understood and may occur at different levels of intracellular signalling pathways.

3.2. TNF- $\alpha$. The first member of the TNF superfamily discovered was TNF- $\alpha$, a pleiotropic proinflammatory cytokine [42]. It plays a crucial role in immune and inflammatory processes, and in endotoxic shock $[33,43]$. TNF- $\alpha$ is synthesised by macrophages and other cells in response to bacterial toxins, inflammatory products, and other invasive stimuli [44]. Its prolonged production is associated with cancer and chronic infections. It has been suggested that a gut with an active injury (e.g. in Crohn's disease or UC) contains an increased number of TNF- $\alpha$ secreting cells [45]. The proinflammatory cytokines, such as TNF- $\alpha$, are typical activators of the canonical NF- $\kappa \mathrm{B}$ signalling cascade, which is activated in response to injury, infection, inflammation, and other stress conditions [46]. In extracts of colorectal tumour tissues resected from human patients, a higher endogenous TNF- $\alpha$ was detected compared to adjacent normal tissue [47]. In addition to its role in inflammation, TNF- $\alpha$ can significantly modulate the proliferation, differentiation, and cell death of colonocytes during cancer progression [48]. 
3.3. TRAIL. TRAIL is an interesting candidate for anticancer therapy because of its ability to selectively induce apoptosis in cancer but not normal cells [49]. TRAIL can interact with at least five different receptors. Two of them, DR4 (TRAIL-R1) and DR5 (TRAIL-R2), signal apoptosis, while decoy receptors DcR1 (TRAIL-R3), DcR2 (TRAIL-R4), and osteoprotegerin (TRAIL-R5) are unable to transmit the apoptotic signal [50].

An important part of TRAIL action is constituted by the regulation of intercellular interactions among the cells of the innate and adaptive immune system and the resulting apoptotic response. TRAIL is expressed on macrophages, dendritic cells, T cells, or NK cells in dependence on their stimulation status, being implicated in immunosuppressive, immunoregulatory, and immune-effector functions. Within this system, TRAIL plays an important role in autoimmune disorders, viral and bacterial infections, and immune surveillance of tumours and metastases [51]. Interestingly, a novel way to target and kill colon and prostate cancer cells in the bloodstream has been reported, using leukocytes presenting TRAIL on their surface along with E-selectin receptor [52].

In addition to acting as a potent tumour-selective inducer of apoptosis, TRAIL is also capable of efficiently triggering the nonapoptotic pathways involving extracellular signalregulated kinases (ERK), c-Jun N-terminal kinases (JNK), p38, phosphoinositide 3-kinase (PI3K)/Akt or NF- $\kappa$ B, which may result in increased proliferation, survival, migration, invasiveness, or inflammation in different normal and/or cancer cell types $[53,54]$. Our results showed that specific inhibitors of the ERK pathway efficiently sensitised human colon cancer cells to TRAIL-induced apoptosis, which was mediated via downregulation of $\mathrm{Mcl}-1$ protein. Moreover, inhibition of the PI3K/Akt pathway in colon cancer cells also resulted in sensitisation to TRAIL-induced apoptosis $[55,56]$. It has recently been shown that cancer cells surviving the fractional killing by TRAIL exhibit NF- $\kappa \mathrm{B}-$ dependent inflammatory phenotypes [57]. Other studies have shown an enhancement of NF- $\kappa$ B signalling in cancer cells resistant to TRAIL-induced apoptosis, which was associated with promotion of tumour metastasis and invasiveness [58].

The expression of TRAIL DRs, and DcRs may significantly change depending on the stage of tumorigenesis or the inflammatory disorders, suggesting their possible functional role in regulating the course of the disease. TRAIL and DR4 were downregulated in enterocytes, and TRAIL was upregulated in mononuclear cells only in IBD but not in the normal colon or appendicitis. This may point to a pathophysiological role of the TRAIL system in IBD [59]. Moreover, DR4 and DR5 were upregulated in colon adenomas and carcinomas compared with adjacent normal epithelial cells [60]. There exist contradictory data showing both a positive and a negative role of the TRAIL/TRAIL-R system in the regulation of cancer cell apoptosis, motility, invasiveness, and metastasis. DR5 has been reported to mediate anoikis (detachment-induced apoptosis) in human colon cancer cells [61]. DR deficiency in mice has been shown to enhance lymph node metastasis of epithelial cancers [62]. On the other hand, the ability of TRAIL and its DRs to promote metastasis in human and mouse CRC has also been demonstrated [63].
This dual role of DRs, and the differences observed in the cell response to TRAIL may depend on tumour type and stage and cell context, or they might be related to activation of the specific kinase pathways. It has been shown by us and others that cell sensitivity to TRAIL-induced apoptosis may be altered significantly during the colon carcinogenesis [64, 65]. Moreover, in some tumour types, the beneficial apoptosisinducing effects of TRAIL may not be easily separated from the unfavourable nonapoptotic properties when using TRAIL in cancer therapy.

3.4. Fas/FasL. The Fas/FasL system is implicated in the aetiology of IBD because the Fas receptor (also called CD95, APO-1/Fas, or TNFRSF6) is highly expressed in the basolateral membrane of intestinal epithelial cells. During this disease, epithelial cell apoptosis is increased [7]. Fas initiates an apoptotic signal to apoptosis-sensitive cells when oligomerised by a natural ligand, FasL, or anti-Fas antibody [66]. FasL is a transmembrane protein that is expressed by lymphocytes, mainly by CD4+ and CD8+ T cells and $\mathrm{B}$ cells, after engagement of the Ag-specific T- or B-cell receptor and macrophages and also by NK cells [67]. It has been proposed that only membrane-bound FasL induces Fas-mediated apoptosis, whereas sFasL triggers nonapoptotic signalling pathways [68]. Activation and infiltration of tumour-specific lymphocytes expressing membrane-bound FasL, primarily tumour-specific CD8+, may be essential for Fas function. Recent results indicated that the colonic mucosa from patients with UC harbours more $\mathrm{T}$ cells than the normal colon tissue. This observation is consistent with human clinical data and animal-based studies, which showed a critical role of $\mathrm{T}$ cells in UC pathogenesis [69]. While Fas is expressed in every colonocyte of the normal colon mucosa, it is downregulated or lost in the majority of colon carcinomas. In contrast to the normal colonic epithelium, many colon carcinoma cell lines are relatively resistant to Fas cross-link [67]. Genomic data indicate that Fas is not focally amplified but significantly deleted across the entire dataset of 3131 tumours, including human CRC [70]. Thus, these data strongly suggest that Fas functions as a tumour suppressor $[71,72]$. It was reported that mice with Fas deficiency in the colon tissue are hypersensitive to induced colitis and mice lacking FasL exhibited a more severe and persistent colitis than normal mice [73]. Several studies showed that cFLIP is an inhibitor of Fas signalling, which enhanced the frequency and decreased latency of subcutaneous tumour growth [67, 74]. However, recent data demonstrated that cFlip is required for intestinal tissue homeostasis in mice. This protein controls the level of activation of caspase- 8 to promote the survival of intestinal epithelial cells. When cFlip was deleted from the intestinal epithelium, the animals died within a few days from severe tissue destruction, epithelial cell death, and intestinal inflammation. The death of intestinal cells was regulated extrinsically and required the presence of death receptor ligands, such as TNF- $\alpha$ and FasL [75]. Fas is a target for the $\mathrm{NF}-\kappa \mathrm{B}$ transcription factor but a direct interaction between $\mathrm{NF}-\kappa \mathrm{B}$ and the Fas promoter in human colon carcinoma cells was not identified [76]. 
Taken together, the ability of TNF family cytokines to induce apoptosis in intestinal epithelial cells seems to be very important. Their sensitivity may be influenced by many other factors and is altered during inflammation and carcinogenesis. Since many cancer cells become resistant to TNF cytokine-mediated killing, much effort has been devoted to find a possibility of overcoming it by combination with other anticancer agents. In addition to chemotherapeutics, the supportive effects of nontoxic dietary compounds seem to be a promising way. In the following parts we summarise recent knowledge about the effects of such compounds in colon inflammation and cancer and their use in combination with TNF family cytokines.

\section{Dietary Factors and Colon Cancer}

It is pointed out that since the Industrial Revolution, humans have fundamentally changed their dietary habits towards increased consumption of animal fat, decreased consumption of antioxidants, and an increased n-6/n-3 PUFA ratio [77]. The imbalance between energy intake and expenditure mainly due to high fat consumption and low fibre intake represents an important factor influencing colon cancer development. Nowadays, it is recognised that excessive lipid uptake in adipocytes leads to hypertrophy and consequently to metabolic dysregulation, hypoxia, inflammation, impaired adipocytokine expression and angiogenesis, insulin resistance, and macrophage recruitment. In obese patients, tumours commonly colocalise with excessive adipose tissue accumulation producing inflammatory mediators, and most of the features of hypertrophic adipose tissue are observed in cancer patients, namely, those with breast and colon cancer $[78,79]$. Using the model of Apc (Min/+) mice, an association of high-fat American-type diet with obesity and an increased number of large polyps was demonstrated. On the other hand, it was also shown that calorie restriction and several bioactive food components, such as n-3 PUFA, can inhibit genetically predisposed CRC $[80,81]$.

4.1. The Role of Polyunsaturated Fatty Acids (PUFAs) in Colon Inflammation and Cancer. It has been shown that the quantitative and qualitative content of essential PUFAs in the diet is highly important $[82,83]$. These PUFAs cannot be synthesised by mammals and their availability depends on external supply. They are divided into two main types of the n-6 and n-3 series. Precursor linoleic acid (LA, 18:2, n-6) found in many plant oils (soybean, sunflower) is desaturated and elongated to other types, mainly arachidonic acid (AA, 20:4). Alpha-linolenic acid (ALA, 18:3, n-3) is a precursor for eicosapentaenoic (EPA, 20:5) or docosahexaenoic (DHA, 22:6) acids, which are also found in fish or algal oils. Excessive amounts of n-6 PUFAs and a high n-6/n-3 ratio, found in Western diets, may promote the pathogenesis of many diseases such as cardiovascular disease, obesity, diabetes, autoimmune disease, inflammation, and cancer [84-86]. Recently, it was reported that the fatty acid profile of visceral white adipose tissue correlates with inflammatory signatures potentially associated with CRC [87].
Ingestion of PUFAs leads to their distribution to virtually every cell in the body and influences the lipid profile and fatty acid composition of plasma, nuclear, and mitochondrial cell membranes. This consequently affects the membrane structure and fluidity, the functions of membrane-bound proteins, and lipid-mediated signalling [88]. In IBD patients and human colorectal adenomas and adenocarcinomas, altered activities of enzymes metabolising endogenous AA, particularly increased expression and activity of PLA2, and COX-2 accompanied by an overproduction of prostaglandin E2 (PGE2) were detected [89] and have been shown to be responsible for immunosuppression and tumour promotion $[31,90]$. Moreover, IBD colon biopsies show a marked increase in both 5-LOX and leukotriene B4 [91]. Both EPA and DHA compete for fatty acid metabolising enzymes with AA and thus are able to inhibit the formation of AA-derived proinflammatory and immunosuppressive eicosanoids [92]. Importantly, EPA and DHA form several own potent antiinflammatory mediators (e.g., resolvins and protectins) [93]. The effects of PUFAs and their metabolites on various levels of cell organisation and their interaction with other endogenous or exogenous factors can finally significantly influence cell proliferation, differentiation, and apoptosis of various cell types [94, 95].

During the last 25 years, hundreds of papers describing the effects of PUFAs on various types of normal and cancer cells, differences between n-6 and n-3 PUFAs, and proposed mechanisms of their action have been published. This large and complex topic is beyond the scope of this review. However, in spite of much contradiction in the literature [96], it is generally thought that high calorie and fat intake are risk factors especially in colon, breast, or prostate cancer development and that n-6 PUFAs (from plant oils rich in LA) can promote inflammation and carcinogenesis [97]. Supplementation of diet with PUFAs can substantially influence cell physiology and cell kinetics, mostly by the modulation of oxidative metabolism and biosynthesis of PUFA metabolites. The particular species of free radicals affect specific phases of carcinogenesis in different ways [98]. The effects of n-6 PUFAs are primarily mediated by AAderived eicosanoids. The anti-inflammatory and anticancer effects of NSAIDs, which function as specific inhibitors of AA metabolism, confirmed the significance of eicosanoids in cancer development $[99,100]$.

On the other hand, there is growing evidence that n-3 PUFAs, namely, DHA and EPA, found in fish and algal oils, exert anti-inflammatory properties, thus suppressing IBD and colon cancer [101-106]. Over the last years, these n-3 PUFA properties were confirmed by experiments with cell cultures and laboratory animals using the introduction of a newly discovered gene encoding $n-3$ fatty acid desaturase (fat-1), which is not normally present in mammals [107].

Nutritionally induced changes in fatty acid composition may result in an increased sensitivity to chemo- and radiotherapy and decreased undesirable side effects [108110]. There is also evidence suggesting that n-3 PUFA may uniquely regulate stem cell signalling pathways and the increased sensitivity of colon cancer cells to chemotherapy by upregulation of colonic differentiation markers [111]. 
There are many papers describing the different mechanisms considered to be responsible for n-3 PUFA effects on cellular and molecular levels [101, 106, 112-114]. In general, there are three major mechanisms suggested to play the main role in n-3 PUFA effects: (1) alteration of cellular membrane phospholipid composition and lipid microdomain functionality, (2) competition for metabolisation enzymes with n-6 PUFAs and thus production of bioactive mediators, eicosanoids, and (3) modulation of intracellular signalling and nuclear receptor activation. These aspects are discussed in a further chapter dealing with the interaction of PUFAs with TNF family cytokines.

4.2. Fibre and Short-Chain Fatty Acids (SCFAs) in Colon Inflammation and Cancer. Dietary fibre increases the gastrointestinal tract biomass, changes the composition of gut flora, and may decrease the risk of metabolic disorders like dyslipidaemia, hypercholesterolaemia, and hyperglycaemia and also substantially influence immune-based actions [115]. Its fermentation by intestinal bacteria leads to the generation of SCFAs propionate, acetate, and butyrate. Butyrate, present in the colonic lumen in millimolar concentration, acts as a principal energy source and a survival factor for normal colon cells. In addition, it possesses anti-inflammatory and antineoplastic properties. Butyrate supplementation dramatically reduced proliferation and induced differentiation and/or cell death in colon cancer cells [116]. In addition to the regulation of basic cytokinetic processes, butyrate has also been shown to affect cell adhesion, morphology, invasiveness, metastasis, oxidative metabolism, angiogenesis, activity of different enzymes, gene expression and chromatin modulation, activity/expression of various transcription factors, and signal transduction molecules. These multiple effects in colon cells were reviewed by us previously [117].

The butyrate action is very complex and still not completely understood. Butyrate is a well-known histone deacetylase (HDAC) inhibitor and thereby regulates gene expression and induces sensitisation effects on cytokine action in colon cancer cells $[118,119]$. Accompanying these changes butyrate influences the cell response to inflammatory stimuli mainly by the inhibition of $\mathrm{NF} \kappa-\mathrm{B}$ and IFN $\gamma$ signalling pathways and an enhancement of peroxisome proliferator-activated receptor $\gamma(\operatorname{PPAR} \gamma)$ expression and activity, leading to the modulation of apoptosis and differentiation [120, 121]. Moreover, it was reported that HDAC inhibitors including butyrate induce autophagy which shares some common signalling pathways and is mutually regulated with apoptosis in colon cancer cells.

The putative mechanisms responsible for the different response to butyrate in normal, IBD- and tumour-derived colon cells may include changes in butyrate transport and uptake, mainly due to a different expression of sodiumcoupled monocarboxylate transporters [122] and the specific G-protein coupled receptor 43 [123]. Butyrate metabolism is impaired in intestinal inflamed mucosa of patients with IBD. Disturbances in butyrate oxidation, the balance between butyrate and glucose oxidation, ROS generation in mitochondria, and differences in the overall cellular context play a role, too $[124,125]$.

\section{Interactive Effects of Dietary Fatty Acids with TNF Family Cytokines}

It is suggested by us and others that dietary fatty acids (such as essential PUFAs or butyrate) and endogenous regulators from the TNF family can mutually interact and thus modulate the behaviour of colon epithelial cells. Such interactions may result in an altered production and activity of proinflammatory TNF family cytokines or an enhancement of their antiproliferative and proapoptotic effects. Moreover, these effects may be different in normal and cancer cells. Therefore, in the following sections we summarise the knowledge about these interactions, their possible mechanisms, and outcomes for intestinal cell behaviour and pathologies. The possible application of such knowledge for the prevention and therapy of colon inflammation and cancer is also outlined. Main mechanisms supposed to play the role in the fatty acid and TNF family cytokine interaction are schematically presented in Figure 1.

5.1. Interaction of TNF Family Cytokines with PUFAs. The effects of TNF family molecules on cancer cells could be significantly modulated by PUFAs and their metabolites. Previously we evidenced the potentiating effects of various inhibitors of AA metabolism on TNF- $\alpha$ induced apoptosis and differentiation in human leukaemic cell lines [126128]. This phenomenon was also verified in human colon epithelial cells [129]. Our further results showed that the pretreatment of human colon cancer HT-29 cells with low doses of AA or DHA may prepare a permissive environment for a more effective apoptotic action of TNF family molecules. Importantly, low concentrations of both $\mathrm{AA}$ and DHA increased the apoptosis induced by anti-Fas antibody or TNF$\alpha$, which involved enhanced ROS production and decrease of mitochondrial membrane potential and caspase activation. Compared to AA, DHA showed more pronounced effects in lower concentration [130]. Similarly, the cotreatment of HT29 cells with DHA enhanced TRAIL-induced apoptosis supporting the mitochondrial intrinsic pathway [131]. Recently, we confirmed these effects using several other colon cell lines (including TRAIL-resistant SW620 cells), which were pretreated with DHA. We clarified the key mechanisms of DHA and TRAIL interaction including the role of mitochondria, specific lipids, and signalling pathways (submitted manuscript). These results are promising, because in spite of the fact that TRAIL may be a selective anticancer agent, many cancer cells are resistant to its effects. This resistance may occur at different levels of intracellular signalling pathways, and manipulation of their individual components such as downregulation of antiapoptotic molecules or upregulation of proapoptotic factors can change the threshold for apoptosis induction by this cytokine [55]. This can be right achieved by combined treatments of TRAIL with selected agents specifically targeting the abovementioned molecules, such as 


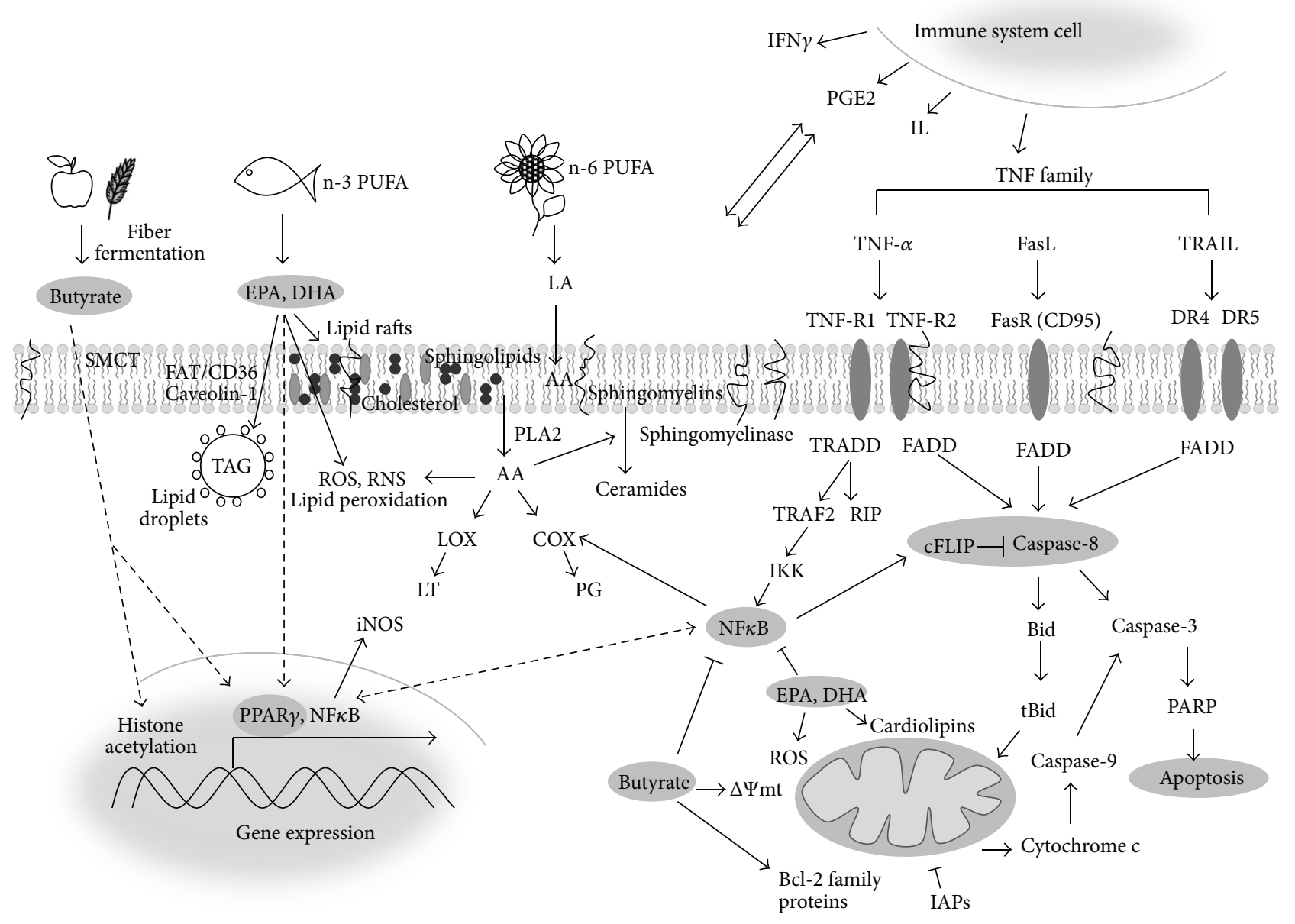

FIGURE 1: Schematic simplified demonstration of the main mechanisms supposed to be involved in fatty acid and TNF family interaction at different levels of colon epithelial cell organisation. Fibre fermentation product butyrate is transported by SMCT into the cells, where it may inhibit histone deacetylation, activate transcription factor PPAR $\gamma$, inhibit NFKB, and affect $\Delta \Psi$ mt and expression and balance of pro- and antiapoptotic members of Bcl-2 family proteins. Dietary PUFAs of the n-6 (LA, AA-plant oils) and n-3 series and (EPA and DHA, fish and algal oils) transported into the cells by FAT/CD36 are stored in lipid droplets in TAG form or incorporated into plasma and mitochondrial membrane lipids thus modulating composition and structure of lipid rafts and caveolae. PUFAs are released from membrane phospholipids by PLA2 and metabolized by COX and LOX enzymes to various types of products such as LTs and PGs. PUFAs can also modulate ceramide production and their metabolism is source of ROS and RNS and induces lipid peroxidation. Incorporation of PUFAs into mitochondrial cardiolipins influences mitochondrial metabolism and induction of apoptosis. EPA and DHA activate PPAR $\gamma$ and inhibit $\mathrm{NF} \kappa \mathrm{B}$, thus suppressing iNOS expression and RNS production. TNF family cytokines TNF- $\alpha$, TRAIL, and FasL bind to their receptors TNFR1 and 2, DR4 and DR5, or FasR (CD95), respectively. Programmed cell death is regulated by formation of DISC consisting of FADD and procaspase-8, whose activation may be inhibited by cFLIP. Cleavage of Bid protein to tBid mediates connection between extrinsic and intrinsic (mitochondrial) apoptotic pathway. Changes in mitochondria (involving cardiolipin modulation), mitochondrial transition pore opening, decrease of $\Delta \Psi \mathrm{mt}$, and production of ROS influence the activation of pro- and antiapoptotic proteins of the Bcl-2 family and release of proapoptotic proteins (e.g., cytochrome c) into the cytosol. Subsequent activation of caspase- 9 and caspase-3, cleavage of PARP, and execution of apoptosis can be inhibited by IAPs. TNF- $\alpha$ activates NF $\kappa$ B via pathway involving TRADD, RIP, TRAF2, and IKK proteins. The interaction between epithelial cells and cells of immune system, which are the source of inflammatory mediators (IFN $\gamma$, IL, and PGE2), is also indicated. The dashed arrows-simplified signalling pathways. AA: arachidonic acid; cFLIP: FLICE-like inhibitory protein; COX: cyclooxygenase; $\triangle \Psi \mathrm{mt}$ : mitochondrial membrane potential; DHA: docosahexaenoic acid; DISC: death-inducing signaling complex; DR: death receptor; EPA: eicosapentaenoic acid; FADD: Fas-associated DD protein; FasL: Fas ligand; FasR: Fas receptor; FAT/CD36: fatty acid translocase; IAPs: inhibitor of apoptosis proteins; IKK: inhibitor of $\mathrm{NF} \kappa \mathrm{B}$ kinase; IFN $\gamma$ : interferon $\gamma$; IL: interleukin; iNOS: inducible nitric oxide synthase; LA: linoleic acid; LOX: lipoxygenase; LT: leukotrienes; NF- $\kappa$ B: nuclear factor $\kappa \mathrm{B}$; PARP: poly-ADP ribose polymerase; PG: prostaglandins; PGE2: prostaglandin E2; PLA2: phospholipase A2; PPAR $\gamma$ : peroxisome proliferator-activated receptor $\gamma$; PUFA: polyunsaturated fatty acids; RIP: receptor-interacting protein; RNS: reactive nitrogen species; ROS: reactive oxygen species; SMCT: sodium-coupled monocarboxylate transporters; TNF: tumor necrosis factor; TNFR: tumor necrosis factor receptor; TRADD: TNFR1-associated death domain protein; TRAF2: TNF receptor-associated factor 2; TRAIL: tumour necrosis factor-related apoptosis-inducing ligand. 
chemotherapeutic DNA damaging drugs $[53,132]$ or fatty acids [131].

Summarising our results we have recognised that the cell response to molecules regulating cytokinetics as well as to lipid compounds is cell type-specific and may depend on the cell genetic background and the level of transformation. In colon cell lines derived from nontumour tissues or tissues on various stages of malignancy we detected a different sensitivity to TNF family cytokines, PUFAs as well as butyrate $[65,133,134]$. Generally, investigation of the molecular mechanisms and cellular specificity of PUFAs as well as TNF family cytokines enables us to determine also the possible mechanisms of their interaction.

PUFAs are actively transported into the cells by fatty acid translocase (FAT/CD36), and their incorporation alters the cellular lipid composition and fatty acid spectrum and shifts redox balance and the formation of various products of lipid metabolism [98]. In response to the elevated fatty acid content, complex and metabolically active organelles called lipid droplets (LDs) are formed. LDs are fundamental components of intracellular lipid homeostasis because they play a role in lipogenesis and lipolysis, serve as an important reservoir of signal molecules, and appear to be directly involved in membrane traffic and phospholipid recycling [135].

DHA, the longest (22 carbons) and the most unsaturated (6 double bonds) PUFA, is rapidly incorporated into the plasma as well as mitochondrial membrane phospholipids and also induces LD formation. It was shown to significantly alter the lipid microdomain (lipid rafts and caveolae) composition and the properties which increase or decrease specific receptors in lipid rafts accompanied by altered phosphorylation and thus activation of receptor and associated signalling kinases [136-138]. For example, after changes in membrane microdomains upon DHA treatment, epidermal growth factor receptor is excluded from caveolin-rich membrane fractions resulting in the subsequent downregulation of ERK signalling in three different cancer models [139]. The position and activity of TNFR, Fas, or DRs may be influenced in a similar way. Our results evidenced that increased DR5 surface expression, relocalisation of DRs to lipid rafts, and accelerated TRAIL internalisation are important for the sensitisation of colon and prostate cancer cells to TRAIL-induced apoptosis by platinum complexes [132]. Attention should be paid when applying TRAIL in combination with other drugs known for their ability to increase the DR surface level in cancer cells, as nonapoptotic signalling might also be increased under some circumstances.

DHA is specifically incorporated into the mitochondrial tetra-acyl phospholipid, cardiolipin (CL). Altered CL unsaturation and oxidative susceptibility of the mitochondrial membrane modulate the binding and activities of associated proteins, mainly of the pro- and antiapoptotic proteins of the $\mathrm{Bcl}-2$ family. Changes of mitochondrial transition pore opening, decreased mitochondrial membrane potential, CL oxidation, and the release of proapoptotic cytochrome $c$ and Apaf1 molecules are necessary for the execution of the intrinsic mitochondrial apoptotic pathway [140, 141]. Thus, in colonocytes and colon cancer cells, DHA alone or in combination with other agents can induce apoptosis by promotion of the mitochondrial apoptotic pathway as reported by us and others [131, 133, 142].

The beneficial effects of n-3 PUFA are of particular interest because IBD patients are very sensitive to nutraceutical approaches [143]. Using a fat-1 transgenic mice model, an inhibitory effect of endogenously synthesised n-3 PUFA on COX-2 gene expression was demonstrated during acute and chronic colitis accompanied by marked reduction in proinflammatory interleukins such as IL- $\alpha$, IL- 6 , and IL18 and molecules endowed with chemotactic activity for granulocytes [144]. Moreover, endogenously synthesised n3 PUFAs in such transgenic animals prevent colon cancer development by several mechanisms [145]. The networking of pathways of eicosanoid formation and inflammatory cytokine production represents a very important issue, but it concerns mainly the interaction of immune cells with other cell types and is not discussed in this review $[146,147]$.

An important consequence of PUFAs and TNF family cytokines interaction is represented by the modulation of proliferation and mainly cell death of cancer cells. Among other mechanisms, the participation of ceramides, which were already shown to play an important role in programmed cell death of cancer cells, was demonstrated [148]. Free AA has been shown to be an important mediator of TNF- $\alpha$ induced apoptosis via activation of sphingomyelinase and formation of ceramides [149]. TNF- $\alpha$-mediated cell killing was inhibited by an increased AA metabolisation by COX-2 overexpression [150] or by blocking endogenous AA release in a mutant cell line with reduced cPLA2 activity [151]. The role of ceramide in Fas-mediated apoptosis has also been well documented [152]. Ceramide enables the Fas receptor to cluster to increase Fas-mediated apoptosis [153] and to modulate Fas receptor activation [72]. Authors identified XIAP and cIAP1 as molecular targets of ceramide.

The higher expression and secretion of various proinflammatory cytokines and their autocrine and paracrine functions play an important role in the activation of transcription factors, which in turn promote tumorigenesis. NF$\kappa \mathrm{B}$ serves as a vital biomolecule that transcribes a number of proinflammatory cytokines and antiapoptotic proteins. NF$\kappa \mathrm{B}$ is also known to play a critical role in the regulation of the inducible nitric oxide synthase (iNOS) gene. iNOS is an enzyme dominantly expressed during inflammatory reactions, and high amounts of nitric oxide $(\mathrm{NO})$ have been demonstrated in pathophysiological processes, such as acute or chronic inflammation and tumorigenesis. Proinflammatory cytokines can also activate Jak3/Stat3 signalling pathways, thereby increasing inflammation and cell survival. The expression of IL- $1 \beta$, IL-2, IL- 4 , IFN $\gamma$, TNF- $\alpha$, iNOS, COX-2, Jak3, Stat 3 , and NF- $\kappa$ B was increased in the early stages of experimental CRC. N-3 PUFAs suppress the activity of NF- $\kappa \mathrm{B}$ and thus reduce the production of proinflammatory enzymes and cytokines, including COX-2, TNF- $\alpha$, and IL$1 \beta$ [102]. The protective role of $n-3$ PUFAs, which suppressed the activity of NF- $\kappa \mathrm{B}$ and iNOS and increased the expression of transforming growth factor $\beta$, thus preventing colitis and CRC, was confirmed using fat-1 transgene mice [154]. 
In vitro studies have shown that n-3 PUFAs inhibit cell proliferation and induce apoptosis in cancer cells through the activation of transcription factors PPARs [155]. They influence lipid homeostasis and may be involved in the regulation of cell differentiation and death. The differential activation of PPAR isoforms $(\alpha, \beta / \delta, \gamma)$ and PPAR-regulated genes by specific dietary fatty acids may be central to their distinct roles in cancer [156]. The data from a human casecontrol study suggest that PPAR $\gamma$ may be associated with many aspects of CRC including insulin- and inflammationrelated mechanisms [157]. In CRC patients, adipocyte dysfunctions creating a proinflammatory environment with upregulated STAT3 and the concomitant decrease of PPAR $\gamma$ and adiponectin in white adipose tissue were detected with respect to healthy subjects. DHA was shown to have protective effects reestablishing the equilibrium between STAT3 and $\operatorname{PPAR} \gamma$ [87].

Wnt $/ \beta$-catenin pathway is constitutively activated in more than $90 \%$ of human CRC. The activated $\beta$-catenin stimulates cell proliferation and survival; however, its antiapoptotic mechanisms are not fully understood. Recently, using a mouse model of inflammation-associated CRC and human colon cancer HCT-116 cells, Han et al. evidenced that the resistance of colon cancer cells to apoptotic effects of TNF- $\alpha$ is mediated by the activated nuclear $\beta$-catenin which blocks caspase cleavage of retinoblastoma protein. Further, the activated $\beta$-catenin can facilitate endosomal trafficking of internalised TNF- $\alpha$ to suppress caspase- 8 activation in colon cancer cells [158]. Since DHA was shown to inhibit the Wnt pathway and activation of $\beta$-catenin, this mechanism may also play a role in its apoptosis-supporting effects [159].

5.2. Interaction of TNF Family Cytokines with Butyrate. Butyrate has been shown to have protective effects on inflammatory diseases such as UC and inflammation-mediated CRC. The ability of butyrate to trigger cancer cell apoptosis is one of the main features of its anticancer activity [160]. It induces apoptosis via mitochondria, efficiently modulating the level of Bcl-2 family and activating of caspases. Upregulation of the proapoptotic Bak and Bax, downregulation of the antiapoptotic $\mathrm{Bcl}-\mathrm{x}_{\mathrm{L}}, \mathrm{XIAP}$, and survivin, or activation of caspase- 3 and Bid after butyrate treatment were detected [161-163]. Butyrate was also shown to effectively modulate the extrinsic apoptotic pathway and to affect the initial steps of DR-mediated apoptosis at the level of DR, FADD, or cFLIP protein [49]. By affecting the level of these proteins, it could effectively contribute to the enhancement of apoptosis induced by TNF- $\alpha$, TRAIL, or FasL [164].

Using various types of colon cancer cell lines, it was reported by us and others that the dual treatment with TNF- $\alpha$ and butyrate significantly increased apoptosis and decreased the differentiation induced by butyrate in HT-29 cells $[165,166]$. Our experiments also documented that the sensitivity of colonic cells to TNF- $\alpha$ and various inhibitors of AA metabolism is dependent on the differentiation status. The apoptotic effect of dual treatment with butyrate and TNF$\alpha$ can be potentiated by several different COX and LOX inhibitors [129].
The butyrate-mediated facilitation of the TNF- $\alpha$ induced death signal was also detected in COLO 205 adenocarcinoma cells, highly resistant to extrinsic apoptosis induced by death ligands $[167,168]$. The immune escape of COLO 205 cells from TNF- $\alpha$ mediated apoptosis is probably caused by extensive shedding of TNFR1 and TNFR2 [169] and by a cFLIP protein inhibitory effect on caspase- 8 activation [170]. The reduction of cFLIP protein and elevated TNFR1 expression after butyrate treatment corresponded with the higher sensitivity of COLO 205 cells to TNF- $\alpha$ induced apoptosis [171].

It could be supposed that butyrate and TNF- $\alpha$ might share similar signalling pathways including phospholipase $\mathrm{C}$ and protein kinase C $[172,173]$. Butyrate-mediated changes of colon cancer cell sensitivity to TNF- $\alpha$ have been associated with the modulation of NF- $\kappa \mathrm{B}$ activity, which had a significant impact on proliferation, apoptosis, and inflammation in colon cancer cells. It was demonstrated that butyrate pretreatment of HT-29, SW480, and SW620 cells inhibits the TNF- $\alpha$ mediated p65 and p50 translocation to the nucleus, probably by suppressing the cellular proteasome activity and subsequently $\mathrm{I} \kappa \mathrm{B}$ degradation through butyrate ability to inhibit HDAC [174-176]. Moreover, butyrate reduced inflammation in experimental colitis in rats [177] and decreased proinflammatory cytokine expression in intestinal biopsies from Crohn's disease patients via NF- $\kappa$ B inactivation [178].

Butyrate pretreatment can lead to a significant enhancement of TRAIL-induced apoptosis in TRAIL-resistant cells [160]. Enhancement of apoptosis after combined treatment with butyrate and TRAIL was described in an HCT-116 colon cancer cell line. Butyrate caused a downregulation of XIAP protein and an upregulation of DR5, but no changes were detected on DR4 levels. Increased levels of DR5 were initiated by the binding of transcriptional factor Spl to DR5 promoter after butyrate treatment [179]. Recently, an increased toxicity against gastrointestinal tumour cells in vitro and in vivo by combined treatment with sorafenib, HDAC inhibitors, and TRAIL was reported. The enhanced TRAIL cell killing correlated with the reduced Akt, ERK 1/2, and mTOR (mammalian target of rapamycin) activity and the enhanced cleavage of caspase- 3 and reduced expression of Mcl-1 and Bcl-X $\mathrm{L}_{\mathrm{L}}[180]$.

Increased apoptosis in the combined treatment of butyrate and TRAIL was studied not only in colon cancer but also in other model systems including breast, bladder, and nervous cancer. Although individual mechanisms are cell type-dependent, several molecules (DR5, DISC, caspase8 , and Bcl-2 family proteins) play a crucial role across the models. Moreover, the combined treatment was not harmful to normal cells of different tissues, compared with their cancer counterparts [181, 182]. In addition, butyrate was reported to sensitise colon cancer cells to Fas-mediated apoptosis, mainly due to increased ROS production $[165,183]$.

Other data showed that inflammation can be affected both on the level of the immune system and colon epithelial cell interaction. In patients with UC it was discovered that butyrate inhibited the binding of HDAC1 to Fas promoter, which was hyperacetylated and led to an upregulation of Fas in T cells. Therefore, butyrate eliminated the source of 
inflammation by induction of T-cell apoptosis. Furthermore, butyrate suppressed IFN- $\gamma$-mediated inflammation in colon epithelial cells by preventing STAT-1 activation and blocking iNOS induction [69].

\section{Importance of Fatty Acids for the Prevention and Therapy of Colon Inflammation and Cancer}

Recently, it has been clear that dietary fatty acids not only serve as an energy source but also represent components which significantly influence physiological and pathophysiological processes from molecular and cellular to organismal levels. These compounds have also been considered as pharmaceutical agents which may have beneficial or detrimental impact on the body and may influence the effects of other drugs $[108,184]$. The research concerning PUFAs as well as butyrate is closely related to the prevention and therapy of serious human diseases including cancer and interferes with other fields such as pharmacology and nutritional and health policy. Therefore, there is more need for a critical global overview and a consideration of the future perspectives $[83,185]$.

There are many reports showing the advantage of $n-3$ PUFAs as components of clinical enteral and parenteral lipid emulsions. Compared to the widely used emulsions from soybean oil containing mostly n-6 linoleic acid, other types with fish oil containing n-3 EPA and DHA were reported to have biological activities beneficial to patients [186, 187]. Many excellent reviews from experimental and clinical studies have been published on this topic, and thus we only summarise that nutritional supplementation with n-3 PUFA may influence inflammation, susceptibility to infection, and immune cell function and thus may affect immunological response, cachexia, and exert beneficial effects on the whole organism, which may then fight better against inflammation and cancer [188-191]. Besides fish oil, algal oil seems to be a better source of n-3 PUFAs due to gastrointestinal complaints of fish oil, especially in high-dose therapy [192]. To refine recommendations for the intake of individual n-3 PUFAs, differential effects of EPA, DHA, and their metabolites may be taken into account. The divergent incorporation into individual cellular lipids, activation of the signalling pathways and transcription factors, or the potency of their metabolites can contribute to diversity in the cellular response [193].

The importance of n-3 PUFAs as well as butyrate in relation to TNF family cytokines lies particularly in their ability to decrease the production of these cytokines and other factors (eicosanoids and interleukins) in the organism, to interfere with their signalling pathways, and thus to prevent the inflammatory response. Supplementation with DHA and EPA allows using lower doses of corticoids in IBD therapy [194].

Cancer anorexia and cachexia are major factors contributing to the weakening of the already compromised immune system of cancer patients. There is evidence suggesting that elevated levels of proinflammatory cytokines are associated with cancer-related cachexia $[195,196]$.
The treatment with fish oil or NSAIDs was shown to attenuate systemic inflammation and improve cachexia because it decreased production of active eicosanoids as well aslevel of proinflammatory and procachectic cytokines [197].

An important aspect is represented by the reported DHA and/or butyrate ability to support apoptosis induced by TNF cytokines, which is promising for use as a supportive anticancer agent. The therapeutic use of the TNF- $\alpha / T N F R$, the FasL/Fas, or TRAIL/DRs in cancer treatment has been hampered by severe side effects [33, 198]. The systemic administration of TNF- $\alpha$ causes a septic shock-like response possibly mediated by NF- $\kappa \mathrm{B}$ activation, and the injection of an agonist antibody to Fas can be lethal. Moreover, many cancer cells are resistant to apoptosis induced by these cytokines $[43,48]$. Thus, particularly the ability of n3 PUFAs to decrease the therapeutic doses, to overcome the resistance, or to improve the overall state of the organism could be considered. Moreover, the interaction with TRAIL overcoming cancer cell resistance and being selective for cancer cells is highly important. However, it is necessary to further investigate and verify these possibilities before future clinical use.

There are studies showing mainly preventive but also potential therapeutic applications of butyrate, which aim to exploit its ability to regulate inflammation, apoptosis, and ion uptake. Anti-inflammatory effects of butyrate were studied in patients with UC or Crohn's disease as well as on animal models, where in several studies it reduced the clinical and inflammatory index [121]. Moreover, its ability to support the effects of other anti-inflammatory and anticancer agents (such as NSAIDs and apoptotic cytokines) is promising for clinical use. The advantages of treatment with butyrate include practically no adverse side effects and its possible oral administration, although its unpleasant taste and odour make it extremely difficult [199].

\section{Conclusion}

From the data described above it appears that the targeted use of a specific type of fat and fibre (PUFAs and butyrate) may have a number of beneficial effects both in physiological and pathophysiological conditions particularly in the intestine. Both PUFAs and fibre (source of butyrate) are natural dietary components which represent a nontoxic way for positive modulation of intestinal cell physiology, improvement of inflammatory conditions and cancer treatment outcomes, and slowing down or preventing the recurrence of IBD or CRC. Important issue represents the ability of dietary fatty acids to modulate production and function of endogenous regulators from TNF family and thus positively or negatively influence the behaviour of intestinal cells. Understanding the molecular mechanisms of both PUFA and butyrate effects and their interaction with specific type of cytokines may help to optimise the composition of clinical nutrition and therapeutical approaches for patients with IBD and intestinal neoplasms. However, as with other agents, they have to be 
applied carefully, based on solid scientific evidence of their mechanisms of action from the molecular and cellular up to the organismal levels.

\section{Abbreviations}

\begin{tabular}{|c|c|}
\hline AA: & Arachidonic acid \\
\hline ALA: & $\alpha$ Linolenic acid \\
\hline APC: & Adenomatous polyposis coli \\
\hline cFLIP: & FLICE-like inhibitory protein \\
\hline CL: & Cardiolipin \\
\hline COX: & Cyclooxygenase \\
\hline CRC: & Colorectal cancer \\
\hline DD: & Death domain \\
\hline DHA: & Docosahexaenoic acid \\
\hline DISC: & Death-inducing signaling complex \\
\hline DR: & Death receptor \\
\hline EPA: & Eicosapentaenoic acid \\
\hline ERK: & Extracellular signal-regulated kinases \\
\hline FAP: & Familial adenomatous polyposis \\
\hline FADD: & Fas-associated DD protein \\
\hline FAT/CD36: & Fatty acid translocase \\
\hline HDACI: & Histone deacetylase inhibitor \\
\hline HIF-1 $\alpha:$ & Hypoxia-inducing factor $1 \alpha$ \\
\hline IAPs: & Inhibitor of apoptosis proteins \\
\hline IBD: & Inflammatory bowel disease \\
\hline IL: & Interleukin \\
\hline iNOS: & Inducible nitric oxide synthase \\
\hline JAK: & Janus kinase \\
\hline IFN: & Interferon \\
\hline JNK: & c-Jun N-terminal kinase \\
\hline LA: & Linoleic acid \\
\hline LD: & Lipid droplet \\
\hline LOX: & Lipoxygenase \\
\hline mTOR: & Mammalian target of rapamycin \\
\hline $\mathrm{NF}-\kappa \mathrm{B}:$ & Nuclear factor $\kappa \mathrm{B}$ \\
\hline NSAIDs: & Nonsteroidal anti-inflammatory drugs \\
\hline PGE2: & Prostaglandin E2 \\
\hline PLA2: & Phospholipase A2 \\
\hline $\operatorname{PPAR} \gamma:$ & Peroxisome proliferator-activated receptor $\gamma$ \\
\hline PUFA: & Polyunsaturated fatty acids \\
\hline RIP: & Receptor-interacting protein \\
\hline RONS: & Reactive oxygen and nitrogen species \\
\hline SCFA: & Short-chain fatty acid \\
\hline STAT: & $\begin{array}{l}\text { Signal transducer and activator of } \\
\text { transcription }\end{array}$ \\
\hline TNF: & Tumor necrosis factor \\
\hline TRAIL: & $\begin{array}{l}\text { Tumour necrosis factor-related } \\
\text { apoptosis-inducing ligand }\end{array}$ \\
\hline UC: & Ulcerative colitis. \\
\hline
\end{tabular}

\section{Conflict of Interests}

The authors declare that there is no conflict of interests regarding the publication of this paper.

\section{Acknowledgments}

The authors apologize to all authors whose work is related to the reviewed topic and could not be cited here due to space limitations. The authors would like to thank Dr. L. Cerveny for the English revision. This work was supported by Grants 13-097665 from Czech Science Foundation and MUNI/A/0927/2013.

\section{References}

[1] F. E. Bertrand, C. W. Angus, W. J. Partis, and G. Sigounas, "Developmental pathways in colon cancer: crosstalk between WNT, BMP, Hedgehog and Notch," Cell Cycle, vol. 11, pp. 43444351, 2012.

[2] C. Gunther, H. Neumann, M. F. Neurath, and C. Becker, "Apoptosis, necrosis and necroptosis: cell death regulation in the intestinal epithelium," Gut, vol. 62, pp. 1062-1071, 2013.

[3] F. E. Ahmed, "Colon cancer: prevalence, screening, gene expression and mutation, and risk factors and assessment," Journal of Environmental Science and Health C: Environmental Carcinogenesis and Ecotoxicology Reviews, vol. 21, no. 2, pp. 65131, 2003.

[4] W. M. Grady and J. M. Carethers, "Genomic and epigenetic instability in colorectal cancer pathogenesis," Gastroenterology, vol. 135, no. 4, pp. 1079-1099, 2008.

[5] S. Lifshitz, S. A. Lamprecht, D. Benharroch, I. Prinsloo, S. PolakCharcon, and B. Schwartz, "Apoptosis (programmed cell death) in colonic cells: from normal to transformed stage," Cancer Letters, vol. 163, no. 2, pp. 229-238, 2001.

[6] B. Zhivotovsky and S. Orrenius, "Carcinogenesis and apoptosis: paradigms and paradoxes," Carcinogenesis, vol. 27, no. 10, pp. 1939-1945, 2006.

[7] L. Chen, S. M. Park, A. V. Tumanov et al., "CD95 promotes tumour growth," Nature, vol. 465, pp. 492-496, 2010.

[8] F. Balkwill and A. Mantovani, "Inflammation and cancer: back to Virchow?" The Lancet, vol. 357, no. 9255, pp. 539-545, 2001.

[9] P. L. Lakatos and L. Lakatos, "Risk for colorectal cancer in ulcerative colitis: changes, causes and management strategies," World Journal of Gastroenterology, vol. 14, no. 25, pp. 3937-3947, 2008.

[10] S. H. Itzkowitz and X. Yio, "Inflammation and cancer-IV. Colorectal cancer in inflammatory bowel disease: the role of inflammation," American Journal of Physiology-Gastrointestinal and Liver Physiology, vol. 287, no. 1, pp. G7-G17, 2004.

[11] U. Gaur and B. B. Aggarwal, "Regulation of proliferation, survival and apoptosis by members of the TNF superfamily," Biochemical Pharmacology, vol. 66, no. 8, pp. 1403-1408, 2003.

[12] P. Boyle and M. E. Leon, "Epidemiology of colorectal cancer," British Medical Bulletin, vol. 64, pp. 1-25, 2002.

[13] T. Yamamoto, M. Nakahigashi, and A. R. Saniabadi, "Review article: diet and inflammatory bowel disease-epidemiology and treatment," Alimentary Pharmacology and Therapeutics, vol. 30, no. 2, pp. 99-112, 2009.

[14] M. F. McEntee and J. Whelan, "Dietary polyunsaturated fatty acids and colorectal neoplasia," Biomedicine and Pharmacother$a p y$, vol. 56, no. 8, pp. 380-387, 2002.

[15] M. P. Weijenberg, M. Lüchtenborg, A. F. P. M. de Goeij et al., "Dietary fat and risk of colon and rectal cancer with aberrant MLH1 expression, APC or KRAS genes," Cancer Causes and Control, vol. 18, no. 8, pp. 865-879, 2007. 
[16] D. Schrenk, "Dietary fiber, low-molecular-weight food constituents and colo-rectal inflammation in animal models-a review," Molecular Nutrition and Food Research, vol. 53, no. 10, pp. 1281-1288, 2009.

[17] H. Putaala, H. Mäkivuokko, K. Tiihonen, and N. Rautonen, "Simulated colon fiber metabolome regulates genes involved in cell cycle, apoptosis, and energy metabolism in human colon cancer cells," Molecular and Cellular Biochemistry, vol. 357, no. 1-2, pp. 235-245, 2011.

[18] G. Sethi, M. K. Shanmugam, L. Ramachandran, A. P. Kumar, and V. Tergaonkar, "Multifaceted link between cancer and inflammation," Bioscience Reports, vol. 32, no. 1, pp. 1-15, 2012.

[19] D. B. Vendramini-Costa and J. E. Carvalho, "Molecular link mechanisms between inflammation and cancer," Current Pharmaceutical Design, vol. 18, pp. 3831-3852, 2012.

[20] T. Chiba, H. Marusawa, and T. Ushijima, "Inflammationassociated cancer development in digestive organs: mechanisms and roles for genetic and epigenetic modulation," Gastroenterology, vol. 143, pp. 550-563, 2012.

[21] S. Danese and A. Mantovani, "Inflammatory bowel disease and intestinal cancer: a paradigm of the Yin-Yang interplay between inflammation and cancer," Oncogene, vol. 29, no. 23, pp. 33133323, 2010.

[22] K. A. Tappenden, "Inflammation and intestinal function: where does it start and what does it mean?" Journal of Parenteral and Enteral Nutrition, vol. 32, no. 6, pp. 648-650, 2008.

[23] A. Andoh, Y. Yagi, M. Shioya, A. Nishida, T. Tsujikawa, and Y. Fujiyama, "Mucosal cytokine network in inflammatory bowel disease," World Journal of Gastroenterology, vol. 14, no. 33, pp. 5154-5161, 2008.

[24] S. Kraus and N. Arber, "Inflammation and colorectal cancer," Current Opinion in Pharmacology, vol. 9, no. 4, pp. 405-410, 2009.

[25] L. Klampfer, "Cytokines, inflammation and colon cancer," Current Cancer Drug Targets, vol. 11, no. 4, pp. 451-464, 2011.

[26] G. Monteleone, F. Pallone, and C. Stolfi, "The dual role of inflammation in colon carcinogenesis," International Journal of Molecular Sciences, vol. 13, pp. 11071-11084, 2012.

[27] A. Rizzo, F. Pallone, G. Monteleone, and M. C. Fantini, "Intestinal inflammation and colorectal cancer: a doubleedged sword?" World Journal of Gastroenterology, vol. 17, no. 26, pp. 3092-3100, 2011.

[28] B. K. Popivanova, K. Kitamura, Y. Wu et al., "Blocking TNF- $\alpha$ in mice reduces colorectal carcinogenesis associated with chronic colitis," The Journal of Clinical Investigation, vol. 118, no. 2, pp. 560-570, 2008.

[29] M. J. Waldner and M. F. Neurath, "Cytokines in colitisassociated cancer: potential drug targets?" Inflammation and Allergy-Drug Targets, vol. 7, no. 3, pp. 187-194, 2008.

[30] S. R. Yan, R. R. Joseph, K. Rosen et al., "Activation of NF- $\kappa$ B following detachment delays apoptosis in intestinal epithelial cells," Oncogene, vol. 24, no. 43, pp. 6482-6491, 2005.

[31] R. S. Chapkin, L. A. Davidson, L. Ly, B. R. Weeks, J. R. Lupton, and D. N. McMurray, "Immunomodulatory effects of (n-3) fatty acids: putative link to inflammation and colon cancer," Journal of Nutrition, vol. 137, no. 1, pp. 200S-204S, 2007.

[32] J. L. McClellan, J. M. Davis, J. L. Steiner et al., "Intestinal inflammatory cytokine response in relation to tumorigenesis in the $A p c^{M i n /+}$ mouse," Cytokine, vol. 57, no. 1, pp. 113-119, 2012.

[33] B. B. Aggarwal, S. C. Gupta, and J. H. Kim, "Historical perspectives on tumor necrosis factor and its superfamily: 25 years later, a golden journey," Blood, vol. 119, no. 3, pp. 651-665, 2012.

[34] A. Bhardwaj and B. B. Aggarwal, "Receptor-mediated choreography of life and death," Journal of Clinical Immunology, vol. 23, no. 5, pp. 317-332, 2003.

[35] H. Walczak and P. H. Krammer, "The CD95 (APO-1/Fas) and the TRAIL (APO-2L) apoptosis systems," Experimental Cell Research, vol. 256, no. 1, pp. 58-66, 2000.

[36] S. Nagata, "Apoptosis by death factor," Cell, vol. 88, no. 3, pp. 355-365, 1997.

[37] M. MacFarlane, "TRAIL-induced signalling and apoptosis," Toxicology Letters, vol. 139, no. 2-3, pp. 89-97, 2003.

[38] N. Özören and W. S. El-Deiry, "Defining characteristics of types I and II apoptotic cells in response to TRAIL," Neoplasia, vol. 4, no. 6, pp. 551-557, 2002.

[39] M. R. Sprick and H. Walczak, "The interplay between the Bcl2 family and death receptor-mediated apoptosis," Biochimica et Biophysica Acta, vol. 1644, no. 2-3, pp. 125-132, 2004.

[40] W. Wu, P. Liu, and J. Li, "Necroptosis: an emerging form of programmed cell death," Critical Reviews in Oncology/Hematology, vol. 82, pp. 249-258, 2012.

[41] P. S. Welz, A. Wullaert, K. Vlantis et al., "FADD prevents RIP3-mediated epithelial cell necrosis and chronic intestinal inflammation," Nature, vol. 477, no. 7364, pp. 330-334, 2011.

[42] B. Beutler and A. Cerami, "Cachectin and tumour necrosis factor as two sides of the same biological coin," Nature, vol. 320, no. 6063 , pp. 584-588, 1986.

[43] M. Jäättelä, "Biology of disease: biologic activities and mechanisms of action of tumor necrosis factor- $\alpha /$ cachectin," Laboratory Investigation, vol. 64, no. 6, pp. 724-742, 1991.

[44] K. J. Tracey and A. Cerami, "Tumor necrosis factor: a pleiotropic cytokine and therapeutic target," Annual Review of Medicine, vol. 45, pp. 491-503, 1994.

[45] H. C. Reinecker, M. Steffen, T. Witthoeft et al., "Enhanced secretion of tumour necrosis factor-alpha, IL- 6 , and IL- $1 \beta$ by isolated lamina propria mononuclear cells from patients with ulcerative colitis and Crohn's disease," Clinical and Experimental Immunology, vol. 94, no. 1, pp. 174-181, 1993.

[46] C. Scheidereit, "I $\kappa \mathrm{B}$ kinase complexes: gateways to NF- $\kappa \mathrm{B}$ activation and transcription," Oncogene, vol. 25, no. 51, pp. 6685-6705, 2006.

[47] A. Numata, T. Minagawa, M. Asano, A. Nakane, H. Katoh, and T. Tanabe, "Functional evaluation of tumor-infiltrating mononuclear cells: detection of endogenous interferon- $\gamma$ and tumor necrosis factor- $\alpha$ in human colorectal adenocarcinomas," Cancer, vol. 68, no. 9, pp. 1937-1943, 1991.

[48] C. V. Zhang, Cell Apoptosis, Nova Science Publishers, Inc., New York, NY, USA, 2007.

[49] G. Mellier, S. Huang, K. Shenoy, and S. Pervaiz, "TRAILing death in cancer," Molecular Aspects of Medicine, vol. 31, no. 1, pp. 93-112, 2010.

[50] S. R. Wiley, K. Schooley, P. J. Smolak et al., "Identification and characterization of a new member of the TNF family that induces apoptosis," Immunity, vol. 3, no. 6, pp. 673-682, 1995.

[51] C. Falschlehner, U. Schaefer, and H. Walczak, "Following TRAIL's path in the immune system," Immunology, vol. 127, no. 2, pp. 145-154, 2009.

[52] M. J. Mitchell, E. Wayne, K. Rana, C. B. Schaffer, and M. R. King, "TRAIL-coated leukocytes that kill cancer cells in the circulation," Proceedings of the National Academy of Sciences of the United States of America, vol. 111, pp. 930-935, 2014. 
[53] A. Vaculova, V. Kaminskyy, E. Jalalvand, O. Surova, and B. Zhivotovsky, "Doxorubicin and etoposide sensitize small cell lung carcinoma cells expressing caspase- 8 to TRAIL," Molecular Cancer, vol. 9, article 87, 2010.

[54] P. Secchiero, A. Gonelli, E. Carnevale et al., "TRAIL promotes the survival and proliferation of primary human vascular endothelial cells by activating the Akt and ERK pathways," Circulation, vol. 107, no. 17, pp. 2250-2256, 2003.

[55] A. Vaculová, J. Hofmanová, K. Souček, and A. Kozubík, "Different modulation of TRAIL-induced apoptosis by inhibition of pro-survival pathways in TRAIL-sensitive and TRAIL-resistant colon cancer cells," FEBS Letters, vol. 580, no. 28-29, pp. 65656569, 2006.

[56] A. Vaculová, J. Hofmanová, J. Zatloukalová, and A. Kozubík, "Differences in TRAIL-induced changes of Mcl-1 expression among distinct human colon epithelial cell lines," Experimental Cell Research, vol. 315, no. 19, pp. 3259-3266, 2009.

[57] D. A. Flusberg, J. Roux, S. L. Spencer, and P. K. Sorger, "Cells surviving fractional killing by TRAIL exhibit transient but sustainable resistance and inflammatory phenotypes," Molecular Biology of the Cell, vol. 24, pp. 2186-2200, 2013.

[58] C. Falschlehner, C. H. Emmerich, B. Gerlach, and H. Walczak, "TRAIL signalling: decisions between life and death," International Journal of Biochemistry and Cell Biology, vol. 39, no. 7-8, pp. 1462-1475, 2007.

[59] S. Brost, R. Koschny, J. Sykora et al., "Differential expression of the TRAIL/TRAIL-receptor system in patients with inflammatory bowel disease," Pathology Research and Practice, vol. 206, no. 1, pp. 43-50, 2010.

[60] J. J. Koornstra, J. H. Kleibeuker, C. M. M. van Geelen et al., "Expression of TRAIL (TNF-related apoptosis-inducing ligand) and its receptors in normal colonic mucosa, adenomas, and carcinomas," Journal of Pathology, vol. 200, no. 3, pp. 327-335, 2003.

[61] L. M. Laguinge, R. N. Samara, W. Wang et al., "DR5 receptor mediates anoikis in human colorectal carcinoma cell lines," Cancer Research, vol. 68, no. 3, pp. 909-917, 2008.

[62] A. Grosse-Wilde, O. Voloshanenko, S. Lawrence Bailey et al., "TRAIL-R deficiency in mice enhances lymph node metastasis without affecting primary tumor development," The Journal of Clinical Investigation, vol. 118, no. 1, pp. 100-110, 2008.

[63] F. J. H. Hoogwater, M. W. Nijkamp, N. Smakman et al., "Oncogenic K-Ras turns death receptors into metastasis-promoting receptors in human and mouse colorectal cancer cells," Gastroenterology, vol. 138, no. 7, pp. 2357-2367, 2010.

[64] A. Hague, D. J. Hicks, F. Hasan et al., "Increased sensitivity to TRAIL-induced apoptosis occurs during the adenoma to carcinoma transition of colorectal carcinogenesis," British Journal of Cancer, vol. 92, no. 4, pp. 736-742, 2005.

[65] J. Hofmanová, A. Vaculová, M. Hyžd’alová, and A. Kozubík, "Response of normal and colon cancer epithelial cells to TNFfamily apoptotic inducers," Oncology Reports, vol. 19, pp. 567573,2008

[66] P. H. Krammer, R. Arnold, and I. N. Lavrik, "Life and death in peripheral T cells," Nature Reviews Immunology, vol. 7, no. 7, pp. 532-542, 2007.

[67] S. I. Abrams, "Positive and negative consequences of Fas/Fas ligand interactions in the antitumor response," Frontiers in Bioscience, vol. 10, pp. 809-821, 2005.

[68] I. N. Lavrik and P. H. Krammer, "Regulation of CD95/Fas signaling at the DISC," Cell Death and Differentiation, vol. 19, no. 1, pp. 36-41, 2012.
[69] M. A. Zimmerman, N. Singh, P. M. Martin et al., "Butyrate suppresses colonic inflammation through HDAC1-dependent Fas upregulation and Fas-mediated apoptosis of T cells," American Journal of Physiology-Gastrointestinal and Liver Physiology, vol. 302, no. 12, pp. G1405-G1415, 2012.

[70] Broad Institute, 2014, http://www.broadinstitute.org/tumorscape/pages/portalHome.jsf.

[71] C. Ruiz-Ruiz, G. Robledo, E. Cano, J. M. Redondo, and A. Lopez-Rivas, "Characterization of p53-mediated up-regulation of CD95 gene expression upon genotoxic treatment in human breast tumor cells," The Journal of Biological Chemistry, vol. 278, no. 34, pp. 31667-31675, 2003.

[72] A. V. Paschall, M. A. Zimmerman, C. M. Torres et al., "Ceramide targets xIAP and cIAP1 to sensitize metastatic colon and breast cancer cells to apoptosis induction to suppress tumor progression," BMC Cancer, vol. 14, article 24, 2014.

[73] F. A. Sayani, C. M. Keenan, M. D. van Sickle et al., "The expression and role of Fas ligand in intestinal inflammation," Neurogastroenterology and Motility, vol. 16, no. 1, pp. 61-74, 2004.

[74] J. P. Medema, J. de Jong, T. van Hall, C. J. M. Melief, and R. Offringa, "Immune escape of tumors in vivo by expression of cellular FLICE- inhibitory protein," Journal of Experimental Medicine, vol. 190, no. 7, pp. 1033-1038, 1999.

[75] N. Wittkopf, C. Gunther, E. Martini et al., "Cellular FLICE-like inhibitory protein secures intestinal epithelial cell survival and immune homeostasis by regulating caspase-8," Gastroenterology, vol. 145, no. 6, pp. 1369-1379, 2013.

[76] F. Liu, K. Bardhan, D. Yang et al., "NF-kappaB directly regulates Fas transcription to modulate Fas-mediated apoptosis and tumor suppression," The Journal of Biological Chemistry, vol. 287, pp. 25530-25540, 2012.

[77] A. P. Simopoulos, "Omega-3 fatty acids in health and disease and in growth and development," American Journal of Clinical Nutrition, vol. 54, no. 3, pp. 438-463, 1991.

[78] P. Matafome, D. Santos-Silva, C. M. Sena, and R. Seica, "Common mechanisms of dysfunctional adipose tissue and obesityrelated cancers," Diabetes/Metabolism Research and Reviews, vol. 29, no. 4, pp. 285-295, 2013.

[79] S. D. Day, R. T. Enos, J. L. McClellan, J. L. Steiner, K. T. Velazquez, and E. A. Murphy, "Linking inflammation to tumorigenesis in a mouse model of high-fat-diet-enhanced colon cancer," Cytokine, vol. 64, pp. 454-462, 2013.

[80] A. E. Tammariello and J. A. Milner, "Mouse models for unraveling the importance of diet in colon cancer prevention," Journal of Nutritional Biochemistry, vol. 21, no. 2, pp. 77-88, 2010.

[81] H. Zeng and D. L. Lazarova, "Obesity-related colon cancer: dietary factors and their mechanisms of anticancer action," Clinical and Experimental Pharmacology and Physiology, vol. 39, no. 2, pp. 161-167, 2012.

[82] P. Flachs, M. Rossmeisl, M. Bryhn, and J. Kopecky, “Cellular and molecular effects of n-3 polyunsaturated fatty acids on adipose tissue biology and metabolism," Clinical Science, vol. 116, no. 1, pp. 1-16, 2009.

[83] A. P. Simopoulos, "Genetic variants in the metabolism of omega- 6 and omega- 3 fatty acids: their role in the determination of nutritional requirements and chronic disease risk," Experimental Biology and Medicine, vol. 235, no. 7, pp. 785-795, 2010.

[84] A. P. Simopoulos, "The importance of the ratio of omega6/omega-3 essential fatty acids," Biomedicine and Pharmacotherapy, vol. 56, no. 8, pp. 365-379, 2002. 
[85] J. X. Kang, "Balance of omega-6/omega-3 essential fatty acids is important for health. The evidence from gene transfer studies," World Review of Nutrition and Dietetics, vol. 95, pp. 93-102, 2005.

[86] L. S. Kremmyda, E. Tvrzicka, B. Stankova, and A. Zak, "Fatty acids as biocompounds: their role in human metabolism, health and disease: a review-part 2: fatty acid physiological roles and applications in human health and disease," Biomedical Papers of the Medical Faculty of the University Palacký, Olomouc, Czechoslovakia, vol. 155, no. 3, pp. 195-218, 2011.

[87] M. D’Archivio, B. Scazzocchio, S. Giammarioli et al., "omega3PUFAs exert anti-inflammatory activity in visceral adipocytes from colorectal cancer patients," PLoS ONE, vol. 8, Article ID e77432, 2013.

[88] D. A. Los and N. Murata, "Membrane fluidity and its roles in the perception of environmental signals," Biochimica et Biophysica Acta, vol. 1666, no. 1-2, pp. 142-157, 2004.

[89] F. A. Sinicrope and S. Gill, "Role of cyclooxygenase-2 in colorectal cancer," Cancer and Metastasis Reviews, vol. 23, no. 1-2, pp. 63-75, 2004.

[90] A. Medeiros, C. Peres-Buzalaf, F. Fortino Verdan, and C. H. Serezani, "Prostaglandin E2 and the suppression of phagocyte innate immune responses in different organs," Mediators of Inflammation, vol. 2012, Article ID 327568, 13 pages, 2012.

[91] A. Barajas-Espinosa, F. Ochoa-Cortes, M. P. Moos, F. D. Ramirez, S. J. Vanner, and C. D. Funk, "Characterization of the cysteinyl leukotriene 2 receptor in novel expression sites of the gastrointestinal tract," American Journal of Pathology, vol. 178, no. 6, pp. 2682-2689, 2011.

[92] G. Hawcroft, P. M. Loadman, A. Belluzzi, and M. A. Hull, "Effect of eicosapentaenoic acid on E-type prostaglandin synthesis and EP4 receptor signaling in human colorectal cancer cells," Neoplasia, vol. 12, no. 8, pp. 618-627, 2010.

[93] C. N. Serhan and N. Chiang, "Endogenous pro-resolving and anti-inflammatory lipid mediators: a new pharmacologic genus," British Journal of Pharmacology, vol. 153, supplement 1 , pp. S200-S215, 2008.

[94] I. L. Rudolph, D. S. Kelley, K. C. Klasing, and K. L. Erickson, "Regulation of cellular differentiation and apoptosis by fatty acids and their metabolites," Nutrition Research, vol. 21, no. 12, pp. 381-393, 2001.

[95] C. P. Diggle, "In vitro studies on the relationship between polyunsaturated fatty acids and cancer: tumour or tissue specific effects?" Progress in Lipid Research, vol. 41, no. 3, pp. 240-253, 2002.

[96] C. H. MacLean, S. J. Newberry, W. A. Mojica et al., "Effects of omega-3 fatty acids on cancer risk: a systematic review," Journal of the American Medical Association, vol. 295, no. 4, pp. 403-415, 2006.

[97] M. A. Moyad, "An introduction to dietary/supplemental omega3 fatty acids for general health and prevention-part II," Urologic Oncology: Seminars and Original Investigations, vol. 23, no. 1, pp. 36-48, 2005.

[98] J. Hofmanová, K. Souček, A. Vaculová, and A. Kozubík, "Fatty acids in the modulation of reactive oxygen species balance in cancer," in Oxidants in Biology: A Question of Balance, G. Valacchi and P. A. Davis, Eds., chapter 6, pp. 129-153, Springer, Dordrecht, The Netherlands, 2008.

[99] F. Abir, S. Alva, D. L. Kaminski, and W. E. Longo, "The role of arachidonic acid regulatory enzymes in colorectal disease," Diseases of the Colon and Rectum, vol. 48, no. 7, pp. 1471-1483, 2005.
[100] A. Lanas and F. Sopeña, "Nonsteroidal anti-inflammatory drugs and lower gastrointestinal complications," Gastroenterology Clinics of North America, vol. 38, no. 2, pp. 333-352, 2009.

[101] J. E. Teitelbaum and W. Allan Walker, "Review: the role of omega 3 fatty acids in intestinal inflammation," Journal of Nutritional Biochemistry, vol. 12, no. 1, pp. 21-32, 2001.

[102] D. H. Jho, S. M. Cole, E. M. Lee, and N. J. Espat, "Role of omega3 fatty acid supplementation in inflammation and malignancy," Integrative Cancer Therapies, vol. 3, no. 2, pp. 98-111, 2004.

[103] S. C. Mills, A. C. Windsor, and S. C. Knight, "The potential interactions between polyunsaturated fatty acids and colonic inflammatory processes," Clinical and Experimental Immunology, vol. 142, no. 2, pp. 216-228, 2005.

[104] B. S. Reddy, C. Burill, and J. Rigotty, "Effect of diets high in $\omega$ 3 and $\omega 6$ fatty acids on initiation and postinitiation stages of colon carcinogenesis," Cancer Research, vol. 51, no. 2, pp. 487491, 1991.

[105] L. A. Davidson, D. V. Nguyen, R. M. Hokanson et al., "Chemopreventive $n-3$ polyunsaturated fatty acids reprogram genetic signatures during colon cancer initiation and progression in the rat," Cancer Research, vol. 64, no. 18, pp. 6797-6804, 2004.

[106] G. Calviello and S. Serini, Dietary Omega-3 Polyunsaturated Fatty Acids and Cancer, Springer, New York, NY, USA, 2010.

[107] C. A. Hudert, K. H. Weylandt, Y. Lu et al., "Transgenic mice rich in endogenous omega-3 fatty acids are protected from colitis," Proceedings of the National Academy of Sciences of the United States of America, vol. 103, no. 30, pp. 11276-11281, 2006.

[108] R. S. Pardini, "Nutritional intervention with omega-3 fatty acids enhances tumor response to anti-neoplastic agents," ChemicoBiological Interactions, vol. 162, no. 2, pp. 89-105, 2006.

[109] M. E. Surette, "The science behind dietary omega-3 fatty acids," Canadian Medical Association Journal, vol. 178, no. 2, pp. 177180, 2008.

[110] G. Calviello, S. Serini, E. Piccioni, and G. Pessina, "Antineoplastic effects of N-3 polyunsaturated fatty acids in combination with drugs and radiotherapy: preventive and therapeutic strategies," Nutrition and Cancer, vol. 61, no. 3, pp. 287-301, 2009.

[111] F. de Carlo, T. R. Witte, W. E. Hardman, and P. P. Claudio, "Omega-3 eicosapentaenoic acid decreases CD133 colon cancer stem-like cell marker expression while increasing sensitivity to chemotherapy," PLoS ONE, vol. 8, Article ID e69760, 2013.

[112] S. C. Larsson, M. Kumlin, M. Ingelman-Sundberg, and A. Wolk, "Dietary long-chain n-3 fatty acids for the prevention of cancer: a review of potential mechanisms," American Journal of Clinical Nutrition, vol. 79, no. 6, pp. 935-945, 2004.

[113] R. S. Chapkin, J. Seo, D. N. McMurray, and J. R. Lupton, "Mechanisms by which docosahexaenoic acid and related fatty acids reduce colon cancer risk and inflammatory disorders of the intestine," Chemistry and Physics of Lipids, vol. 153, no. 1, pp. 14-23, 2008.

[114] B. Skender, A. H. Vaculová, and J. Hofmanová, "Docosahexaenoic fatty acid (DHA) in the regulation of colon cell growth and cell death: a review," Biomedical Papers of the Medical Faculty of the University Palacký, Olomouc, Czechoslovakia, vol. 156, no. 3, pp. 186-199, 2012.

[115] M. M. Kaczmarczyk, M. J. Miller, and G. G. Freund, "The health benefits of dietary fiber: beyond the usual suspects of type 2 diabetes mellitus, cardiovascular disease and color cancer," Metabolism: Clinical and Experimental, vol. 61, pp. 1058-1066, 2012. 
[116] H. M. Hamer, D. Jonkers, K. Venema, S. Vanhoutvin, F. J. Troost, and R.-J. Brummer, "Review article: the role of butyrate on colonic function," Alimentary Pharmacology and Therapeutics, vol. 27, no. 2, pp. 104-119, 2008.

[117] J. Hofmanová, A. Vaculová, and A. Kozubík, "Regulation of the metabolism of polyunsaturated fatty acids and butyrate in colon cancer cells," Current Pharmaceutical Biotechnology, vol. 14, no. 3, pp. 274-288, 2013.

[118] X. Tong, L. Yin, and C. Giardina, "Butyrate suppresses Cox2 activation in colon cancer cells through HDAC inhibition," Biochemical and Biophysical Research Communications, vol. 317, no. 2, pp. 463-471, 2004.

[119] N. T. Ventham, N. A. Kennedy, E. R. Nimmo, and J. Satsangi, "Beyond gene discovery in inflammatory bowel disease: the emerging role of epigenetics," Gastroenterology, vol. 145, pp. 293-308, 2013.

[120] M. C. Daroqui and L. H. Augenlicht, "Transcriptional attenuation in colon carcinoma cells in response to butyrate," Cancer Prevention Research, vol. 3, no. 10, pp. 1292-1302, 2010.

[121] R. B. Canani, M. D. Costanzo, L. Leone, M. Pedata, R. Meli, and A. Calignano, "Potential beneficial effects of butyrate in intestinal and extraintestinal diseases," World Journal of Gastroenterology, vol. 17, no. 12, pp. 1519-1528, 2011.

[122] V. Ganapathy, M. Thangaraju, E. Gopal et al., "Sodium-coupled monocarboxylate transporters in normal tissues and in cancer," AAPS Journal, vol. 10, no. 1, pp. 193-199, 2008.

[123] S. I. Karaki, H. Tazoe, H. Hayashi et al., "Expression of the shortchain fatty acid receptor, GPR43, in the human colon," Journal of Molecular Histology, vol. 39, no. 2, pp. 135-142, 2008.

[124] R. Thibault, F. Blachier, B. Darcy-Vrillon, P. de Coppet, A. Bourreille, and J.-P. Segain, "Butyrate utilization by the colonic mucosa in inflammatory bowel diseases: a transport deficiency," Inflammatory Bowel Diseases, vol. 16, no. 4, pp. 684-695, 2010.

[125] M. Andriamihaja, C. Chaumontet, D. Tome, and F. Blachier, "Butyrate metabolism in human colon carcinoma cells: implications concerning its growth-inhibitory effect," Journal of Cellular Physiology, vol. 218, no. 1, pp. 58-65, 2009.

[126] J. Vondráček, M. A. Sheard, P. Krejčí, K. Minksová, J. Hofmanová, and A. Kozubík, "Modulation of death receptormediated apoptosis in differentiating human myeloid leukemia HL-60 cells," Journal of Leukocyte Biology, vol. 69, pp. 794-802, 2001.

[127] J. Štika, J. Vondráček, J. Hofmanová, V. Šimek, and A. Kozubík, "MK-886 enhances tumour necrosis factor-alpha-induced differentiation and apoptosis," Cancer Letters, vol. 237, pp. 263-271, 2006.

[128] J. Procházková, L. Stixová, K. Souček, J. Hofmanová, and A. Kozubík, "Monocytic differentiation of leukemic HL-60 cells induced by co-treatment with TNF- $\alpha$ and MK886 requires activation of pro-apoptotic machinery," European Journal of Haematology, vol. 83, no. 1, pp. 35-47, 2009.

[129] M. Kovaříková, J. Hofmanová, K. Souček, and A. Kozubík, “The effects of TNF- $\alpha$ and inhibitors of arachidonic acid metabolism on human colon HT-29 cells depend on differentiation status," Differentiation, vol. 72, no. 1, pp. 23-31, 2004.

[130] J. Hofmanová, A. Vaculová, and A. Kozubík, "Polyunsaturated fatty acids sensitize human colon adenocarcinoma HT-29 cells to death receptor-mediated apoptosis," Cancer Letters, vol. 218, no. 1, pp. 33-41, 2005.

[131] A. Vaculová, J. Hofmanová, L. Anděra, and A. Kozubík, “TRAIL and docosahexaenoic acid cooperate to induce HT-29 colon cancer cell death," Cancer Letters, vol. 229, pp. 43-48, 2005.
[132] O. Vondálová Blanářová, I. Jelínková, A. Szöor et al., “Cisplatin and a potent platinum(IV) complex-mediated enhancement of TRAIL-induced cancer cells killing is associated with modulation of upstream events in the extrinsic apoptotic pathway," Carcinogenesis, vol. 32, no. 1, pp. 42-51, 2011.

[133] J. Hofmanová, A. Vaculová, Z. Koubková, M. Hýžd’alová, and A. Kozubík, "Human fetal colon cells and colon cancer cells respond differently to butyrate and PUFAs," Molecular Nutrition \& Food Research, vol. 53, supplement 1, pp. S102-S113, 2009.

[134] L. Kočí, M. Hýžd’alová, A. Vaculová, J. Hofmanová, and A. Kozubík, "Detachment-mediated resistance to TRAIL-induced apoptosis is associated with stimulation of the PI3K/Akt pathway in fetal and adenocarcinoma epithelial colon cells," Cytokine, vol. 55, no. 1, pp. 34-39, 2011.

[135] M. T. Accioly, P. Pacheco, C. M. Maya-Monteiro et al., "Lipid bodies are reservoirs of cyclooxygenase-2 and sites of prostaglandin-E2 synthesis in colon cancer cells," Cancer Research, vol. 68, no. 6, pp. 1732-1740, 2008.

[136] D. W. L. Ma, J. Seo, L. A. Davidson et al., "n-3 PUFA alter caveolae lipid composition and resident protein localization in mouse colon," The FASEB Journal, vol. 18, no. 9, pp. 1040-1042, 2004.

[137] W. Stillwell, S. R. Shaikh, M. Zerouga, R. Siddiqui, and S. R. Wassal, "Docosahexaenoic acid affects cell signaling by altering lipid rafts," Reproduction Nutrition Development, vol. 45, no. 5, pp. 559-579, 2005.

[138] J. Seo, R. Barhoumi, A. E. Johnson, J. R. Lupton, and R. S. Chapkin, "Docosahexaenoic acid selectively inhibits plasma membrane targeting of lipidated proteins," The FASEB Journal, vol. 20, no. 6, pp. 770-772, 2006.

[139] K. R. Rogers, K. D. Kikawa, M. Mouradian et al., "Docosahexaenoic acid alters epidermal growth factor receptor-related signaling by disrupting its lipid raft association," Carcinogenesis, vol. 31, no. 9, pp. 1523-1530, 2010.

[140] V. E. Kagan, Y. Y. Tyurina, H. Bayir et al., "The "pro-apoptotic genies" get out of mitochondria: oxidative lipidomics and redox activity of cytochrome c/cardiolipin complexes," ChemicoBiological Interactions, vol. 163, no. 1-2, pp. 15-28, 2006.

[141] S. Rohrbach, "Effects of dietary polyunsaturated fatty acids on mitochondria," Current Pharmaceutical Design, vol. 15, no. 36, pp. 4103-4116, 2009.

[142] M. Y. Hong, R. S. Chapkin, R. Barhoumi et al., "Fish oil increases mitochondrial phospholipid unsaturation, upregulating reactive oxygen species and apoptosis in rat colonocytes," Carcinogenesis, vol. 23, no. 11, pp. 1919-1925, 2002.

[143] K. Mbodji, C. Charpentier, C. Guerin et al., "Adjunct therapy of n-3 fatty acids to 5-ASA ameliorates inflammatory score and decreases NF-kappaB in rats with TNBS-induced colitis," The Journal of Nutritional Biochemistry, vol. 24, pp. 700-705, 2013.

[144] C. Gravaghi, K. M. D. la Perle, P. Ogrodwski et al., "Cox-2 expression, PGE2 and cytokines production are inhibited by endogenously synthesized n-3 PUFAs in inflamed colon of fat1 mice," Journal of Nutritional Biochemistry, vol. 22, no. 4, pp. 360-365, 2011.

[145] A. Algamas-Dimantov, D. Davidovsky, J. Ben-Ari et al., "Amelioration of diabesity-induced colorectal ontogenesis by omega3 fatty acids in mice," The Journal of Lipid Research, vol. 53, pp. 1056-1070, 2012.

[146] S. N. Meydani, "Dietary modulation of cytokine production and biologic functions," Nutrition Reviews, vol. 48, no. 10, pp. 361$369,1990$. 
[147] D. A. Ribardo, J. W. Peterson, and A. K. Chopra, "Phospholipase A2-activating protein-an important regulatory molecule in modulating cyclooxygenase-2 and tumor necrosis factor production during inflammation," Indian Journal of Experimental Biology, vol. 40, no. 2, pp. 129-138, 2002.

[148] T. Sassa, S. Suto, Y. Okayasu, and A. Kihara, "A shift in sphingolipid composition from C24 to C16 increases susceptibility to apoptosis in HeLa cells," Biochimica et Biophysica Acta, vol. 1821, no. 7, pp. 1031-1037, 2012.

[149] M. Hayakawa, N. Ishida, K. Takeuchi et al., "Arachidonic acidselective cytosolic phospholipase A2 is crucial in the cytotoxic action of tumor necrosis factor," The Journal of Biological Chemistry, vol. 268, no. 15, pp. 11290-11295, 1993.

[150] Y. Cao, A. T. Pearman, G. A. Zimmerman, T. M. McIntyre, and S. M. Prescott, "Intracellular unesterified arachidonic acid signals apoptosis," Proceedings of the National Academy of Sciences of the United States of America, vol. 97, no. 21, pp. 11280$11285,2000$.

[151] G. L. Bannenberg, "Therapeutic applicability of anti-inflammatory and proresolving polyunsaturated fatty acid-derived lipid mediators," TheScientificWorldJOURNAL, vol. 10, pp. 676-712, 2010.

[152] J. E. Kinsella, "Lipids, membrane receptors, and enzymes: effects of dietary fatty acids," Journal of Parenteral and Enteral Nutrition, vol. 14, no. 5, pp. 200S-217S, 1990.

[153] V. di Marzo, "Arachidonic acid and eicosanoids as targets and effectors in second messenger interactions," Prostaglandins Leukotrienes and Essential Fatty Acids, vol. 53, no. 4, pp. 239254, 1995.

[154] J. Nowak, K. H. Weylandt, P. Habbel et al., "Colitis-associated colon tumorigenesis is suppressed in transgenic mice rich in endogenous n-3 fatty acids," Carcinogenesis, vol. 28, no. 9, pp. 1991-1995, 2007.

[155] H. Sampath and J. M. Ntambi, "Polyunsaturated fatty acid regulation of genes of lipid metabolism," Annual Review of Nutrition, vol. 25, pp. 317-340, 2005.

[156] I. J. Edwards and J. T. O'Flaherty, "Omega-3 fatty acids and PPAR $\gamma$ in cancer," PPAR Research, vol. 2008, Article ID 358052, 14 pages, 2008.

[157] S. A. Kliewer, S. S. Sundseth, S. A. Jones et al., "Fatty acids and eicosanoids regulate gene expression through direct interactions with peroxisome proliferator-activated receptors $\alpha$ and $\gamma$," Proceedings of the National Academy of Sciences of the United States of America, vol. 94, no. 9, pp. 4318-4323, 1997.

[158] J. Han, R. C. Soletti, A. Sadarangani et al., "Nuclear expression of beta-catenin promotes RB stability and resistance to TNFinduced apoptosis in colon cancer cells," Molecular Cancer Research, vol. 11, pp. 207-218, 2013.

[159] B. A. Narayanan, N. K. Narayanan, B. Simi, and B. S. Reddy, "Modulation of inducible nitric oxide synthase and related proinflammatory genes by the omega-3 fatty acid docosahexaenoic acid in human colon cancer cells," Cancer Research, vol. 63, no. 5, pp. 972-979, 2003.

[160] A. Hernandez, R. Thomas, F. Smith et al., "Butyrate sensitizes human colon cancer cells to TRAIL-mediated apoptosis," Surgery, vol. 130, no. 2, pp. 265-272, 2001.

[161] F. M. Ruemmele, S. Dionne, I. Qureshi, D. S. R. Sarma, E. Levy, and E. G. Seidman, "Butyrate mediates Caco-2 cell apoptosis via up-regulation of pro-apoptotic BAK and inducing caspase3 mediated cleavage of poly-(ADP-ribose) polymerase (PARP)," Cell Death and Differentiation, vol. 6, no. 8, pp. 729-735, 1999.
[162] S. A. Jones, R. N. Butler, I. R. Sanderson, and J. W. Wilson, "The effect of specific caspase inhibitors on TNF- $\alpha$ and butyrateinduced apoptosis of intestinal epithelial cells," Experimental Cell Research, vol. 292, no. 1, pp. 29-39, 2004.

[163] S. Orzechowska, B. Pajak, B. Gajkowska, and A. Orzechowski, "Cholesterol level determines viability and mitogenicity, but it does not affect sodium butyrate-dependent sensitization of Colo 205 cells to TNF- $\alpha$-induced apoptosis," Oncology Reports, vol. 25, no. 2, pp. 573-582, 2011.

[164] S. E. F. Tran, T. H. Holmström, M. Ahonen, V.-M. Kähäri, and J. E. Eriksson, "MAPK/ERK overrides the apoptotic signaling from Fas, TNF, and TRAIL receptors," The Journal of Biological Chemistry, vol. 276, no. 19, pp. 16484-16490, 2001.

[165] C. Giardina, H. Boulares, and M. S. Inan, "NSAIDs and butyrate sensitize a human colorectal cancer cell line to TNF- $\alpha$ and Fas ligation: the role of reactive oxygen species," Biochimica et Biophysica Acta, vol. 1448, no. 3, pp. 425-438, 1999.

[166] M. Kovaříková, J. Pacherník, J. Hofmanová, Z. Zadák, and A. Kozubík, "TNF-alpha modulates the differentiation induced by butyrate in the HT-29 human colon adenocarcinoma cell line," European Journal of Cancer, vol. 36, no. 14, pp. 1844-1852, 2000.

[167] J. Gong, D. Yang, S. Kohanim, R. Humphreys, L. Broemeling, and R. Kurzrock, "Novel in vivo imaging shows up-regulation of death receptors by paclitaxel and correlates with enhanced antitumor effects of receptor agonist antibodies," Molecular Cancer Therapeutics, vol. 5, no. 12, pp. 2991-3000, 2006.

[168] B. Pajak, B. Gajkowska, and A. Orzechowski, "Position of STAT$1 \alpha$ in cycloheximide-dependent apoptosis triggered by TNF- $\alpha$ in human colorectal COLO 205 cancer cell line; role of polyphenolic compounds," Journal of Physiology and Pharmacology, vol. 56, supplement 3, pp. 119-141, 2005.

[169] M. A. Lombard, T. L. Wallace, M. F. Kubicek et al., "Synthetic matrix metalloproteinase inhibitors and tissue inhibitor of metalloproteinase (TIMP)-2, but not TIMP-1, inhibit shedding of tumor necrosis factor- $\alpha$ receptors in a human colon adenocarcinoma (Colo 205) cell line," Cancer Research, vol. 58, no. 17, pp. 4001-4007, 1998.

[170] B. Pajak, B. Gajkowska, and A. Orzechowski, "Cycloheximidemediated sensitization to TNF- $\alpha$-induced apoptosis in human colorectal cancer cell line COLO 205; role of FLIP and metabolic inhibitors," Journal of Physiology and Pharmacology, vol. 56, supplement 3, pp. 101-118, 2005.

[171] B. Pajak and A. Orzechowski, "IFN-alpha competes with TNFalpha for STAT-1alpha; molecular basis for immune escape of human colon adenocarcinoma COLO 205 cells," Oncology Reports, vol. 18, no. 4, pp. 1039-1045, 2007.

[172] P. Cesaro, E. Raiteri, M. Démoz et al., "Expression of protein kinase $\mathrm{C} \beta 1$ confers resistance to TNF $\alpha$ - and paclitaxel-induced apoptosis in HT-29 colon carcinoma cells," International Journal of Cancer, vol. 93, no. 2, pp. 179-184, 2001.

[173] O. C. Velázquez, R. W. Seto, and J. L. Rombeau, “The scientific rationale and clinical application of short-chain fatty acids and medium-chain triacylglycerols," Proceedings of the Nutrition Society, vol. 55, no. 1, pp. 49-78, 1996.

[174] M. S. Inan, R. J. Rasoulpour, L. Yin, A. K. Hubbard, D. W. Rosenberg, and C. Giardina, "The luminal short-chain fatty acid butyrate modulates NF- $\kappa$ B activity in a human colonic epithelial cell line," Gastroenterology, vol. 118, no. 4, pp. 724-734, 2000.

[175] L. Yin, G. Laevsky, and C. Giardina, "Butyrate suppression of colonocyte NF- $\kappa$ B activation and cellular proteasome activity," The Journal of Biological Chemistry, vol. 276, no. 48, pp. 4464144646, 2001. 
[176] M. Hýžd’alová, J. Hofmanová, J. Pacherník, A. Vaculová, and A. Kozubík, "The interaction of butyrate with TNF-alpha during differentiation and apoptosis of colon epithelial cells: role of NFkappaB activation," Cytokine, vol. 44, pp. 33-43, 2008.

[177] J. D. Butzner, R. Parmar, C. J. Bell, and V. Dalal, "Butyrate enema therapy stimulates mucosal repair in experimental colitis in the rat," Gut, vol. 38, no. 4, pp. 568-573, 1996.

[178] J. P. Segain, D. Raingeard de la Blétière, A. Bourreille et al., "Butyrate inhibits inflammatory responses through $\mathrm{NF} \kappa \mathrm{B}$ inhibition: implications for Crohn's disease," Gut, vol. 47, no. 3, pp. 397-403, 2000.

[179] Y. H. Kim, J. W. Park, J. Y. Lee, and T. K. Kwon, "Sodium butyrate sensitizes TRAIL-mediated apoptosis by induction of transcription from the DR5 gene promoter through Spl sites in colon cancer cells," Carcinogenesis, vol. 25, no. 10, pp. 1813-1820, 2004.

[180] H. A. Hamed, Y. Yamaguchi, P. B. Fisher, S. Grant, and P. Dent, "Sorafenib and HDAC inhibitors synergize with TRAIL to kill tumor cells," Journal of Cellular Physiology, vol. 228, no. 10, pp. 1996-2005, 2013.

[181] J. K. Earel Jr., R. L. VanOosten, and T. S. Griffith, "Histone deacetylase inhibitors modulate the sensitivity of tumor necrosis factor-related apoptosis-inducing ligand-resistant bladder tumor cells," Cancer Research, vol. 66, no. 1, pp. 499-507, 2006.

[182] A. Bangert, S. Cristofanon, I. Eckhardt et al., "Histone deacetylase inhibitors sensitize glioblastoma cells to TRAIL-induced apoptosis by c-myc-mediated downregulation of cFLIP," Oncogene, vol. 31, pp. 4677-4688, 2012.

[183] C. Giardina and M. S. Inan, "Nonsteroidal anti-inflammatory drugs, short-chain fatty acids, and reactive oxygen metabolism in human colorectal cancer cells," Biochimica et Biophysica Acta, vol. 1401, no. 3, pp. 277-288, 1998.

[184] Y. M. Dupertuis, M. M. Meguid, and C. Pichard, "Advancing from immunonutrition to a pharmaconutrition: a gigantic challenge," Current Opinion in Clinical Nutrition and Metabolic Care, vol. 12, no. 4, pp. 398-403, 2009.

[185] B. Lands, "A critique of paradoxes in current advice on dietary lipids," Progress in Lipid Research, vol. 47, no. 2, pp. 77-106, 2008.

[186] A. Hagi, M. Nakayama, W. Shinzaki, S. Haji, and H. Ohyanagi, "Effects of the $\omega-6: \omega-3$ fatty acid ratio of fat emulsions on the fatty acid composition in cell membranes and the antiinflammatory action," Journal of Parenteral and Enteral Nutrition, vol. 34, no. 3, pp. 263-270, 2010.

[187] Y. Y. Han, S. L. Lai, W. J. Ko, C. H. Chou, and H. S. Lai, "Effects of fish oil on inflammatory modulation in surgical intensive care unit patients," Nutrition in Clinical Practice, vol. 27, no. 1, pp. 9198, 2012.

[188] G. J. A. Wanten and P. C. Calder, "Immune modulation by parenteral lipid emulsions," American Journal of Clinical Nutrition, vol. 85, no. 5, pp. 1171-1184, 2007.

[189] I. M. Berquin, I. J. Edwards, and Y. Q. Chen, "Multi-targeted therapy of cancer by omega-3 fatty acids," Cancer Letters, vol. 269, no. 2, pp. 363-377, 2008.

[190] P. C. Calder, "Symposium 4: hot topics in parenteral nutrition. Rationale for using new lipid emulsions in parenteral nutrition and a review of the trials performed in adults," Proceedings of the Nutrition Society, vol. 68, no. 3, pp. 252-260, 2009.

[191] D. L. Waitzberg and R. S. Torrinhas, "Fish oil lipid emulsions and immune response: what clinicians need to know," Nutrition in Clinical Practice, vol. 24, no. 4, pp. 487-499, 2009.
[192] V. A. van Beelen, B. Spenkelink, H. Mooibroek et al., "An n-3 PUFA-rich microalgal oil diet protects to a similar extent as a fish oil-rich diet against AOM-induced colonic aberrant crypt foci in F344 rats," Food and Chemical Toxicology, vol. 47, no. 2, pp. 316-320, 2009.

[193] F. D. Russell and C. S. Burgin-Maunder, "Distinguishing health benefits of eicosapentaenoic and docosahexaenoic acids," Marine Drugs, vol. 10, pp. 2535-2559, 2012.

[194] R. Garib, P. Garla, R. S. Torrinhas, P. L. Bertevello, A. F. Logullo, and D. L. Waitzberg, "Effects of parenteral fish oil lipid emulsions on colon morphology and cytokine expression after experimental colitis," Nutrición Hospitalaria, vol. 28, no. 3, pp. 849-856, 2013.

[195] M. J. Tisdale, “The 'cancer cachectic factor," Supportive Care in Cancer, vol. 11, no. 2, pp. 73-78, 2003.

[196] B. Pajak, S. Orzechowska, B. Pijet et al., "Crossroads of cytokine signaling-the chase to stop muscle cachexia," Journal of Physiology and Pharmacology, vol. 59, supplement 9, pp. 251-264, 2008.

[197] C. Deans and S. J. Wigmore, "Systemic inflammation, cachexia and prognosis in patients with cancer," Current Opinion in Clinical Nutrition and Metabolic Care, vol. 8, no. 3, pp. 265-269, 2005.

[198] F. Balkwill, “TNF- $\alpha$ in promotion and progression of cancer," Cancer and Metastasis Reviews, vol. 25, no. 3, pp. 409-416, 2006.

[199] R. Raqib, P. Sarker, A. Mily et al., "Efficacy of sodium butyrate adjunct therapy in shigellosis: a randomized, double-blind, placebo-controlled clinical trial," BMC Infectious Diseases, vol. 12, article 111, 2012. 


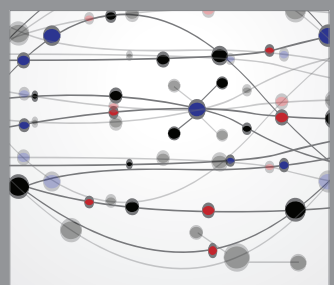

The Scientific World Journal
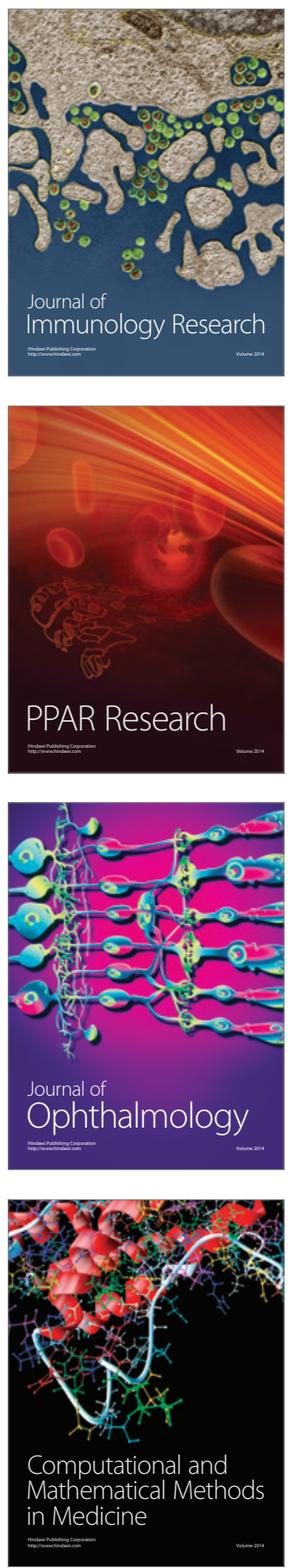

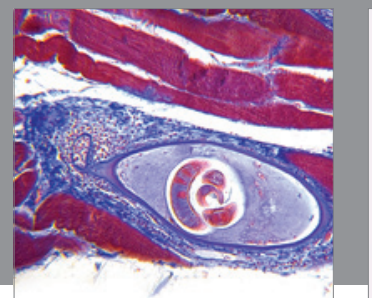

Gastroenterology

Research and Practice
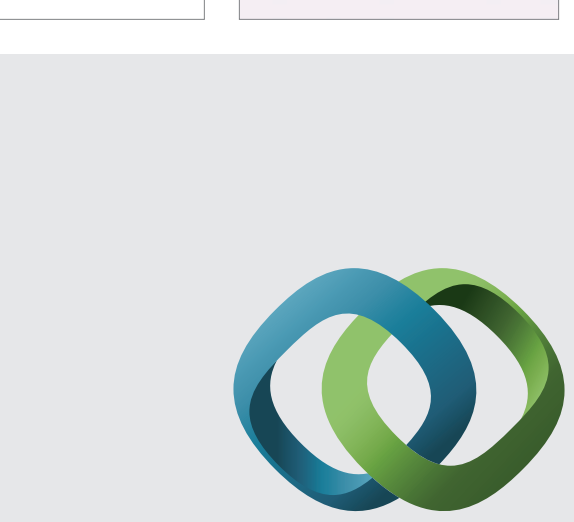

\section{Hindawi}

Submit your manuscripts at

http://www.hindawi.com
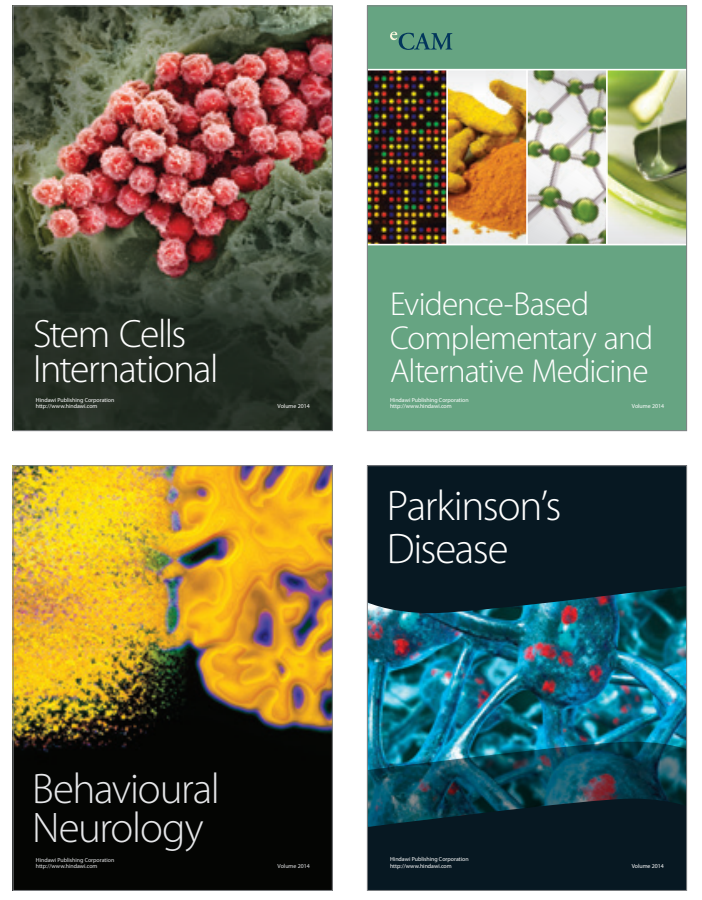
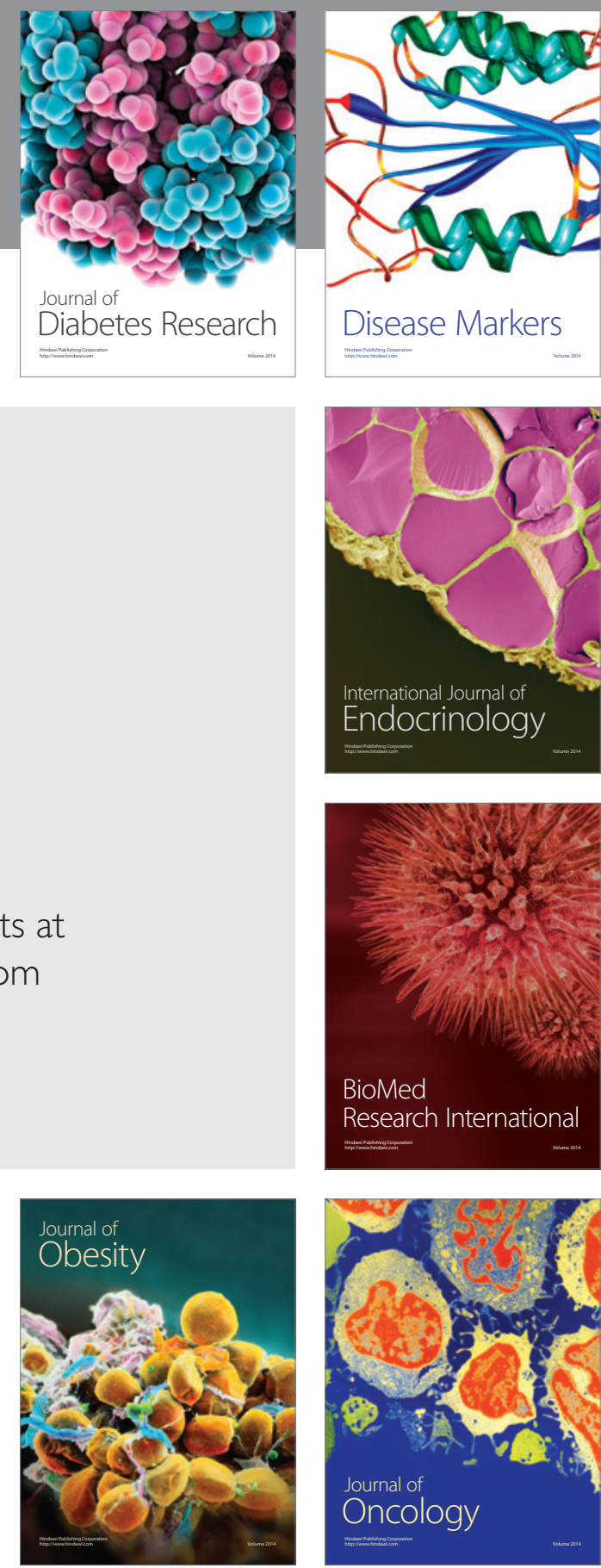

Disease Markers
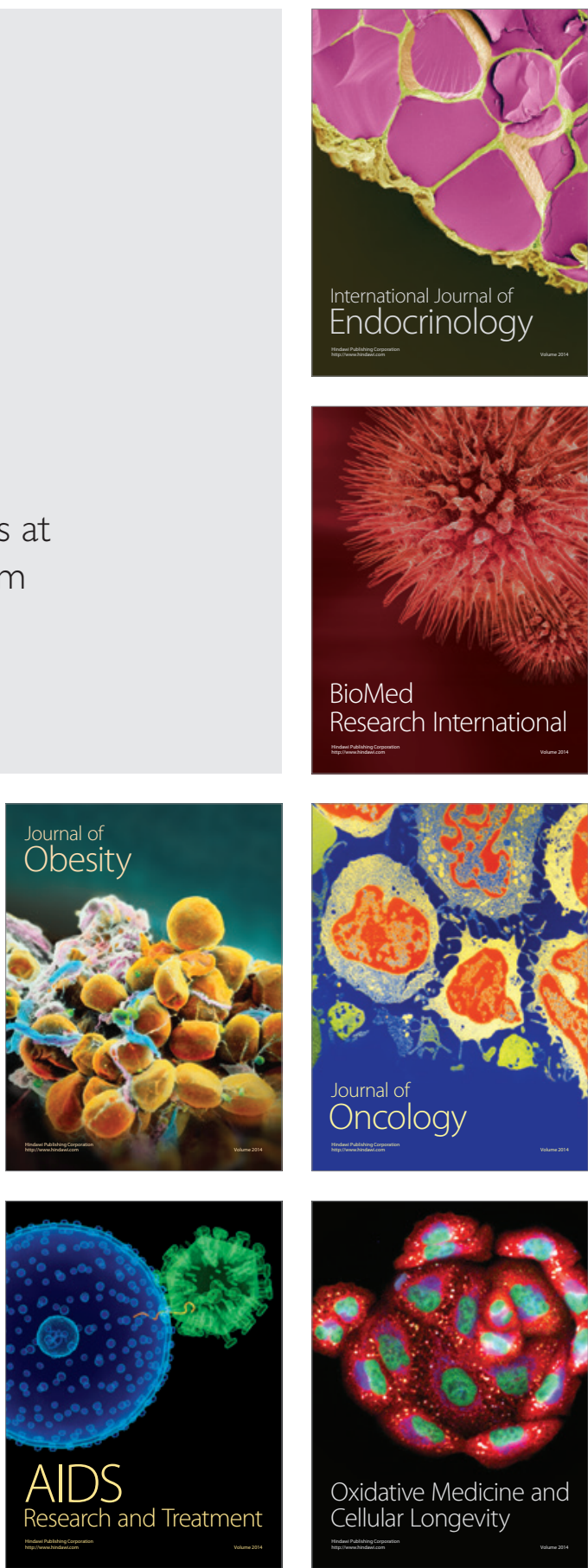